\title{
What Happens If It Changes Color When It Moves?: The Nature of Chromatic Input to Macaque Visual Area MT
}

\author{
Karen R. Dobkins and Thomas D. Albright \\ Vision Center Laboratory, The Salk Institute for Biological Studies, La Jolla, California 92037
}

Neurons in the middle temporal visual area (MT) of macaque cerebral cortex are highly selective for the direction of motion but not the color of a moving stimulus. Recent experiments have shown, however, that the directional selectivity of many MT neurons persists even when a moving stimulus is defined solely by chromatic variation (Charies and Logothetis, 1989; Saito et al., 1989; Dobkins and Albright, 1991a,b; Movshon et al., 1991; Gegenfurtner et al., 1994). To illuminate the mechanisms by which area MT uses color as a cue for motion correspondence, we recorded from MT neurons while rhesus monkeys viewed an "apparent motion" stimulus in which red/green sine wave gratings underwent contrast reversal each time they were displaced in a particular direction. Under such conditions, correspondence based upon chromatically defined borders conflicts with correspondence based upon conservation of chromatic sign. When our heterochromatic stimuli possessed sufficient luminance modulation, MT neurons responded best to motion in the direction for which the sign of luminance (and chromatic) contrast was preserved. At isoluminance, however, two different chromatic influences were revealed. First, when stimuli underwent small spatial displacements, directional selectivity was elicited by movement of the stimulus in the direction of the nearest chromatically defined border, even though the sign of chromatic contrast at that border alternated over time. Under these conditions, MT neurons apparently exploited information about image borders defined by chromatic contrast while sacrificing information about the colors that make up those borders. By contrast, when chromatically defined borders provided only ambiguous information about direction of motion, MT neurons were capable of using information about the sign of chromatic contrast to detect direction of motion. The results from these experiments suggest the existence of a hybrid mechanism, one in which both signed and unsigned chromatic signals contribute to motion processing in visual area MT.

IKey words: color, motion correspondence, neurophysiology, extrastriate area MT, parvocellular, magnocellular, signed and unsigned chromatic borders]

Received Aug. 24, 1993; revised Jan. 26, 1994; accepted Feb. 8, 1994

This work was supported by NIH Grant EY07605, a McKnight Neuroscience Development Award (T.D.A.), and a Fight-For-Sight Summer Fellowship (K.R.D.) We thank J. Costanza for superb technical assistance. We are also grateful to $G$ Stoner and D. MacLeod for helpful discussions and to D. Teller and K. Gegenfurtner for comments on the manuscript.

Correspondence should be addressed to Karen R. Dobkins, The Salk Institute P.O. Box 85800, San Diego, CA 92186.

Copyright $(C) 1994$ Society for Neuroscience $0270-6474 / 94 / 144854-17 \$ 05.00 / 0$
Because the chromatic properties of an image afford salient and reliable means for distinguishing objects, they hold the potential to facilitate detection of object motion. It is widely believed, however, that the neural representations of image color and motion are largely segregated in the primate visual system. Two anatomically distinct streams - magnocellular and parvocellular-originate in the retina and remain largely segregated through several stages of visual processing (Hubel and Wiesel, 1972; Lund and Boothe, 1975; Lund et al., 1975; Livingstone and Hubel, 1984; DeYoe and Van Essen, 1985; Shipp and Zeki, 1985; Livingstone and Hubel, 1987a). Neurophysiological studies have led to the suggestion that the magnocellular system is primarily involved in the processing of motion, while the parvocellular system is involved in the processing of image color and form (Gouras, 1968, 1969; Zeki, 1974; De Monasterio and Gouras, 1975; Schiller and Malpeli, 1978; De Monasterio, 1978; Derrington and Lennie, 1984; Derrington et al., 1984; Livingstone and Hubel, 1984; Tootell et al., 1988; Tootell and Hamilton, 1989; Corbetta et al., 1990; Zeki et al., 1991).

There have been numerous attempts to explore the functional implications of this magnocellular/parvocellular dichotomy in both psychophysical and neurophysiological experiments. A popular strategy has been to utilize moving visual stimuli that contain only chromatic cues for form. Because such "isoluminant" patterns are believed to selectively activate the parvocellular stream, their movement is predicted to be undetectable by motion-sensitive neurons in the magnocellular stream. The results of psychophysical experiments, however, have been equivocal on this point. While the quality of perceived motion is often reported to be impaired at isoluminance (e.g., Ramachandran and Gregory, 1978; Cavanagh et al., 1984; Livingstone and Hubcl, 1987b; Teller and Lindsey, 1993), under most conditions motion is still perceived (Cavanagh and Favreau, 1985; Derrington and Badcock, 1985; Mullen and Baker, 1985; Cavanagh and Anstis, 1988, 1991; Simpson, 1990; Dobkins and Albright, 1993) and direction can be accurately discriminated (Sato, 1988; Mullen and Boulton, 1989; Lindsey and Teller, 1990; Dobkins and Albright, 1993).

Relevant neurophysiological studies have focused on the properties of neurons in the middle temporal area (MT) of primate visual cortex. Area MT, which is part of the dorsal cortical stream, receives predominantly magnocellular input (Maunsell et al., 1990) and is recognized as a key component of the neural substrate for motion perception. The vast majority of MT neurons are highly selective for direction of motion, yet show little evidence of selectivity for either the color or form of a visual stimulus (Zeki, 1974; Baker et al., 1981; Van Essen et al., 1981; Maunsell and Van Essen, 1983a; Nlbright, 1984). The lack of color selectivity in these directionally selective neurons has been 
heralded as evidence for the segregation of color and motion processing pathways. Only recently, however, has attention been given to the possibility that directionally selective neurons encode the motion of objects defined by color while possessing no selectivity for color per se. In support of this possibility, which has considerable value in a functional sense (Albright, 1992), it has been shown that some MT neurons respond to moving isoluminant patterns (Charles and Logothetis, 1989; Saito et al., 1989; Dobkins and Albright, 1990, 1991a,b; Movshon et al., 1991; Gegenfurtner et al., 1994).

There are at least two means by which chromatic information could influence directional selectivity in area MT. The simplest possibility is that motion correspondence is established using chromatically defined boundaries in an image. This "unsigned" chromatic contrast hypothesis supposes that chromatic contrast is used to establish object boundaries at an early stage of visual processing. Subsequent motion processing areas, like MT, have access to these chromatically defined boundaries but information about the colors themselves is not forwarded through the motion pathway; the sign of chromatic contrast is lost. A more significant role for chromatic information is assumed by our "signed" chromatic contrast hypothesis. According to this scheme, object color per se is a determinant of motion correspondence.

To a first approximation, the unsigned hypothesis is consistent with the type of chromatic signals known to be carried within early stages of the magnocellular pathway. A salient feature of the response properties of M-type retinal ganglion cells (Lee et al., 1988, 1989a-c; Lee et al., 1990) and neurons in the magnocellular laminae of the LGN (Schiller and Culby, 1983; Derrington et al., 1984; Hurlbert et al., 1987; Logothetis et al., 1990) is a modulation of firing rate in response to pure chromatic flicker that occurs at twice the flicker frequency. These "frequency doubling" responses signal a chromatic change within the receptive field without regard for the polarity of the change. This insensitivity to sign of chromatic contrast is also evidenced by studies that have used chromatic stimuli in spatial opposition; retinal M cells (Gouras and Eggers, 1982; Shapley and Kaplan, 1989; Kaiser et al., 1990; Valberg et al., 1992) and magnocellular LGN neurons (Kruger, 1979; Shapley and Kaplan, 1989; Hubel and Livingstone, 1990) respond to chromatically defined image contours, yet are unselective for the sign of chromatic contrast. By contrast, retinal P cells (De Monasterio and Gouras, 1975; Gouras and Zrenner, 1979, 1981) and parvocellular LGN neurons (De Valois et al., 1966; Wiesel and Hubel, 1966) are selective for the sign of chromatic contrast. Their properties are, in this respect, far more compatible with the signed chromatic contrast hypothesis.

Prior experiments investigating chromatic motion correspondence have confounded the differential predictions of the signed and unsigned hypotheses. It is generally the case-in the real world and in experiments that employ moving heterochromatic patterns - that both chromatically defined image contours and the specific colors that define those contours move in concert. Such stimuli thus fail to discriminate between our two hypotheses. This limitation is illustrated graphically in Figure $1 \mathrm{~A}$.

To address this problem we have developed methods that allow us to independently evaluate the two potential chromatic mechanisms. Our stimuli consist of heterochromatic sine wave gratings that undergo repetitive chromatic contrast sign reversal while moving. Under such conditions, motion correspondence based upon conservation of chromatic sign is placed in direct opposition to correspondence based upon chromatically defined
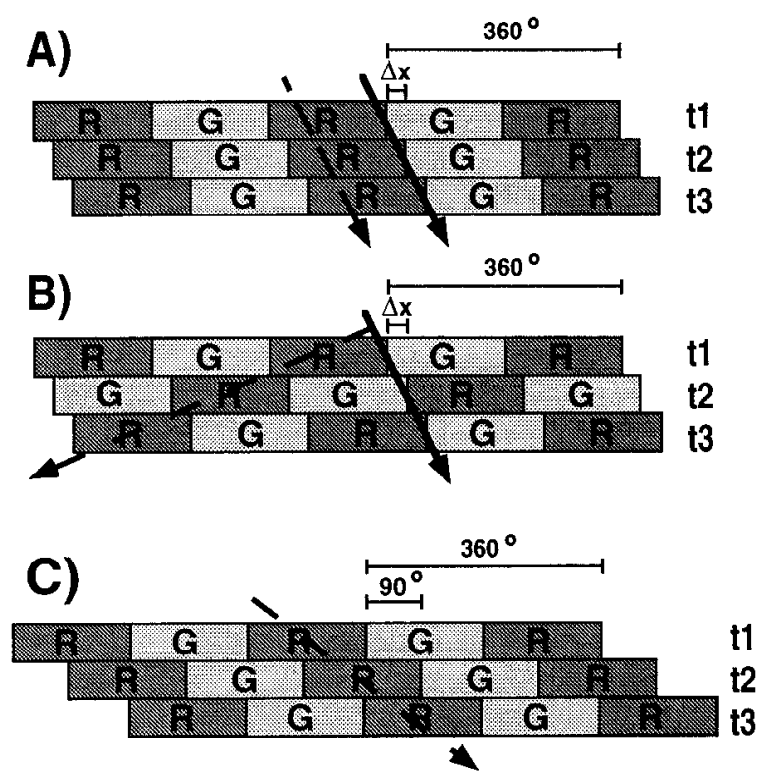

Figure 1. Schematic depiction of "apparent motion" stimuli used to characterize chromatic influences on motion responses in MT. Actual stimuli are red/green $(R / G)$ sine wave gratings $(0.49 \mathrm{cycle} /$ degree $)$. Three lemporal frames $(t I, t 2, t 3)$ are shown. Spatial displacement $(\Delta x)$ is the phase angle (out of $360^{\circ}$ ) the gratings are displaced on each frame. $A$, Conventional drifting chromatic grating. Rightward motion is detectable from spatiotemporal correspondence of either chromatically defined contours (solid arrow) or actual color identity (dashed arrow). $B$, Chromatic grating that undergoes contrast reversal while moving. Motion of the closer "unsigned" chromatically defined boundary is rightward (solid arrow) while motion of the "signed" chromatic cue is leftward (dashed arrow). $C, 90^{\circ}$ (ambiguous) phase displacement. Chromatically defined boundaries provide ambiguous information about direction of motion (a chromatically defined border at $t l$ is equidistant from either of two potential chromatically defincd border matches at $t 2$ ). Under these conditions, a consistent signal indicating direction of motion can only be obtained if information about sign of chromatic contrast is utilized.

image contours. Using these novel stimuli, we sought to determine whether responses of MT neurons support the use of signed or unsigned chromatic cues for motion correspondence. The results define conditions under which color influences directional selectivity in area MT. Moreover, as a counterpart to our previous psychophysical findings (Dobkins and Albright, 1993), these results suggest the existence of a hybrid mechanism: one in which both signed and unsigned chromatic contrast signals contribute to cortical motion processing.

\section{General Method}

\section{Apparatus}

All visual stimuli were generated using a high-resolution, high-speed computer video display and digital frame buffer (Pepper SGT, Number Nine Computer Corp: $640 \times 480$ pixels, analog RGB output, 8 bits/ gun). The controller resided in an AT-class (80386) personal computer, and it permitted 256 simultaneously displayable colors or luminance levels (sclectcd from a palette of 16 million). Stimuli were displayed on a 20 inch analog RGB video monitor (Phillips C2064-AS, $60 \mathrm{~Hz}$, noninterlaced). The voltage/luminance relationship was linearized independently for each of the three guns in the display (Watson et al., 1986). Stimulus generation operated under the charge of a PDP 11/73, which provided coded instructions for selection and timing of visual stimuli produced by the graphics device. The PDP $11 / 73$ was also used for data acquisition, analysis, and behavioral control. 


\section{Animal preparation}

Subjects. Our subjects were three adult female rhesus monkeys (Macaca mulatta). The protocols used in these experiments have been approved by the Salk Institute Animal Care and Use Committee, and they conform to USDA regulations and NIH guidelines for the humane care and use of laboratory animals.

Surgical preparation and wound maintenance. Monkeys were surgically prepared for training and physiological recording using conventional techniques (e.g., Albright et al., 1984; Bruce and Goldberg, 1985). All surgical procedures were performed under aseptic conditions using barbiturate anesthesia (sodium pentobarbital, $25 \mathrm{mg} / \mathrm{kg}$ i.v. initially, followed by continuous infusion of $3.5 \mathrm{mg} / \mathrm{kg} / \mathrm{hr}$ ). Two stainless stccl recording cylinders and a post for head restraint were affixed to the skull with dental acrylic and stainless steel screws. Cylinders were positioned bilaterally over parietal lobe regions (centered at approximately AP -4 $\mathrm{mm}, \mathrm{ML} 17 \mathrm{~mm}$ ) to allow microelectrode penetration into area MT parallel to the dorsal-ventral axis. The cylinders were capped and the skin drawn up around the margin of the cranial implant. A search coil for measuring eye position (Cooner Wire Co.) was surgically implanted in one eye using the method of Judge et al. (1980). The leads of the coil were soldered to a two-pin miniconnector (Powell Electronics) and affixed to the cranial implant with dental acrylic. Animals were given prophylactic antibiotics [during surgery: $30 \mathrm{mg} / \mathrm{kg}$ Keflin (cephalothin sodium), i.v., $3 \times$ at $2 \mathrm{hr}$ intervals; post-op: $25-50 \mathrm{mg} / \mathrm{kg} \mathrm{Keflex} \mathrm{(ce-}$ phalexin), orally at $12 \mathrm{hr}$ intervals for $3 \mathrm{~d}$ ] and postsurgical analgesics (buprenorphine, $0.03 \mathrm{mg} / \mathrm{kg}, 2 \times$ daily for $3 \mathrm{~d}$ ). The ophthalmic wound was treated by application of an ophthalmic antibiotic (chloramphenicol, 1\%). After healing, the cranial wound was treated daily by removal of hair, cleansing, and application of a topical antibiotic (nitrofurazone, $0.2 \%$ in water-soluble powder).

After an appropriate fixation training period (criterion performance on visual fixation in the presence of visual testing stimuli; see below) and 1 week before the first neurophysiological recording session, the animal was again anesthetized and prepared for aseptic surgery as described above. One of the recording cylinders was opened and an $8 \mathrm{~mm}$ diameter hole was drilled through the skull to allow electrode passage into area MT.

Behavioral training. Animals were trained to fixate a small $\left(0.3^{\circ} \mathrm{di}-\right.$ ameter) spot of light on the video display in the presence of moving visual stimuli for the duration of a trial (up to $3 \mathrm{sec}$ ). Animals were seated in a standard primate chair (Crist Instruments) in a quiet lighttight room facing the $60 \mathrm{~cm}$ distant video monitor. Head movements were prevented by bolting the implanted headpost to the frame of the primate chair. Performance on the fixation task was monitored by continuously recording eye position using the magnetic search coil technique (Robinson, 1963). Upon successful completion of a trial animals were given a small (approximately $0.15 \mathrm{ml}$ ) juice reward. Once each animal reached a criterion level of performance $(95 \%$ correct) on this task, neurophysiological experiments were begun.

\section{Elcctrophysiological recording and stimulus presentation}

Paralyene-coated tungsten microelectrodes (Frederick Haer, Brunswick, ME) with exposed tips of $10 \mu \mathrm{m}$ or less were used to record extracellular potentials from single isolated neurons. Electrodes were lowered into the brain through a stainless-steel guide tube by way of a hydraulic microdrive. The guide tube was lowered through the skull opening to penetrate the dura and the microelectrode was passed down through the guide tube to cortical area MT. The electrode, guide tube, and microdrive assembly were attached to the recording chamber by way of an $x-y$ stage aligned with the AP and ML stereotaxic axes. Amplified electrical activity from the cortex was passed through a window discriminator (Bak Electronics) and into a digital oscilloscope. Levels of spontaneous activity, receptive field sizes, position relative to sulci and proportion of cells highly selective for direction of motion were all criteria used to establish that our recordings were, in fact, from area MT.

Once an MT neuron was isolated, its receptive field was mapped using a high contrast luminance-defined bar $\left(85 \mathrm{~cd} / \mathrm{m}^{2}\right.$ on a background of $\left.<1 \mathrm{~cd} / \mathrm{m}^{2}\right)$. The length, width, orientation, speed, and position of this bar were under the experimenter's direct control using a joystick manipulandum. Through this means receptive field boundaries were estimated and the best ("preferred") direction of motion was determined for the ncuron. Following this preliminary assessment, visual stimuli were centered on the geometric center of the receptive field. The fixation spot was repositioned such that the receptive field center (and stimulus center) were aligned with the center of the video display. Neuronal responses were collected during movement of stimuli in preferred and "nonpreferred" $\left(180^{\circ}\right.$ opposed) directions. Stimuli were presented in a pseudorandom sequence for a total of five trials for each stimulus type. Most neurons were studied until all relevant stimulus conditions were completcd-typically less than $1 \mathrm{hr}$. Data collcction from somc neurons was discontinued prematurely because they became injured or poorly isolated during the course of testing.

\section{Data analysis}

The measure of response was the mcan firing rate averaged over five trials of stimulus presentation. An index of directional selectivity (DI) was used to quantify the degree to which each neuron could discriminate preferred from nonpreferred motion: $D I=(P-N P) /(P+N P)$, where $P$ is the firing rate of the neuron in response to motion in its preferred direction and NP is the firing rate in response to motion in its nonpreferred direction. Using this definition, a 2:1 ratio between $P$ and NP responses yields a DI of 0.33 . Note that DIs defined in this manner yield values that are lower than those obtained using a more conventional index: $\mathrm{DI}=1-(\mathrm{NP} / \mathrm{P})$, for which a $2: 1$ ratio between $\mathrm{P}$ and $\mathrm{NP}$ yields a DI of 0.50 (e.g., Maunsell and Van Essen, 1983a; Albright, 1984). We chose this alternate definition since it yields positive and negative DIs of equal magnitude. To estimate the population response, direction indices were averaged across neurons within each stimulus condition. This was performed separately for each of the three monkeys.

\section{Visual stimulation}

Chromatic channel activation and construction of heterochromatic gratings. The C.I.E. chromaticity coordinates for our stimulus display monitor were red $(0.618,0.350)$, green $(0.280,0.605)$, and bluc $(0.152$, $0.067)$. All chromatic stimuli were produced by differential modulation of only the monitor's red and green phosphors, which caused negligible differential activation of S cone photoreceptors but produced $14 \%$ and $34 \%$ cone contrast modulation in $\mathrm{L}$ and $\mathrm{M}$ cones, respectively (Smith and Pokorny, 1972, 1975; Boynton, 1986).

Heterochromatic gratings were produced by summing sinusoidal "mono-phosphor" luminance modulations of the red and green phosphors. The two sinusoids were of identical spatial frequency and orientation but of opposite phase. Once summed in this manner the luminance ratio between the two colors is dependent upon the mean luminances and amplitudes (modulation depths) of the composite monophosphor sinusoids. In our experiments the luminance contrast level was varied by differentially adjusting the mean luminances of the red and green sinusoids such that the mean luminance of the resultant heterochromatic stimulus was held constant at $8.1 \mathrm{~cd} / \mathrm{m}^{2}$. For one monkey (Lefty), a slightly different procedure was used to manipulate luminance contrast level: the red mean luminance was held constant while the green mean luminance varied. For this monkey, therefore, luminance of the heterochromatic grating covaried with the mean luminance of the green phosphor and ranged from 5.3 to $11.2 \mathrm{~cd} / \mathrm{m}^{2}$. Red and green sinusoids were always of equal modulation depth. Luminance contrast of the resultant heterochromatic grating is expressed as modulation depth * $\left[\left(G_{\text {mean }}-R_{\text {mean }}\right) /\left(G_{\text {mean }}+R_{\text {mcan }}\right)\right]$. Using this metric, luminance contrast can be either positive or negative, depending upon which of the two phosphor primaries is brighter. That the luminance modulation in these gratings was indeed sinusoidal was verified by measuring luminance as a function of spatial phase using a standard spot photometer (United Detector Technology, Hawthorne, $\mathrm{C} \Lambda$ ). By differentially varying the means of the two component sinusoids, it was always possible to find a combination for which luminance was invariant with spatial phase - the photometric isolumimant point.

Chromatic contrast describes the fraction of the potential chromatic modulation between the two primaries and is a function of their individual luminance modulation depths (which were always equal to one another). The point at which the amplitudes of the red and green primaries equaled their respective means was considered $100 \%$ chromatic contrast (e.g., Logothetis et al., 1990). This assignment is arbitrary, although it is the maximum contrast attainable from our monitor. Under these conditions, $L$ and $M$ cone contrasts were $14 \%$ and $34 \%$, respertively (root mean squared cone contrast $=26 \%$ ). Because of measurable lability of monitor luminance at low levels, mono-phosphor luminance modulations, hence chromatic contrast, was fixed at $90 \%$.

Construction of achromatic gratings. Visual stimuli that varied only 
in their luminance content ("achromatic" yellow/black gratings) were produced by summing sinusoidal luminance modulations of the red and green phosphors, of identical spatial frequency and orientation, but in phase with one another. Luminance contrast in these stimuli was manipulated by simultaneously varying the modulation depths of both the red and green sinusoids.

General. Moving stimuli were of the "apparent motion" type, that is, gratings were displaced by discrete spatial and temporal intervals, both within a range that normally renders a clear percept of motion (Kolers, 1972) and elicits responses in MT neurons (Mikami et al., 1986; Newsome et al., 1986). In practice, movement was achieved by spatial phase offset at regular intervals occurring in synchrony with the vertical refresh of the video monitor (i.e., at multiples of $16.67 \mathrm{msec}$ ). Frame duration is the interval of time over which a static frame of the stimulus was presented. For the experiments reported herein, frame duration was set at $33.33 \mathrm{msec}$ (i.e., spatial phase offset coincident with every other vertical refresh, or 30 frames/sec).

The spatial frequency of all heterochromatic and achromatic gratings was 0.49 cycle/degree. This spatial frequency is known to provide strong activation of motion mechanisms (Watson et al., 1980; Newsome et al., 1983; Cavanagh et al., 1984; Graham, 1989). All stimuli were circular, subtended $10^{\circ}$ of visual angle (4.9 total cycles), and were viewed binocularly with natural pupils from a distance of $60 \mathrm{~cm}$. The illuminated background portion of the monitor subtended a rectangular region $35^{\circ}$ by $26^{\circ}$ with a uniform luminance of $<1 \mathrm{~cd} / \mathrm{m}^{2}$. The mean luminance of the stimulus aperture during the intertrial interval was $<1 \mathrm{~cd} / \mathrm{m}^{2}$.

\section{Experiment I: chromatic contrast sign reversal}

The spatiotemporal profile of the stimulus used for this experiment is illustrated in Figure $1 B$. With each spatial displacement, sign of chromatic contrast is inverted (red becomes green, green becomes red, etc.). Under these conditions there are two opposing cues for motion correspondence. The first is a contrastreversing (unsigned) chromatically defined contour (moving rightward in Fig. $1 B$ ). The second is invariant (signed) chromatic contrast (moving leftward in Fig. $1 B$ ). It was our objective in using this technique to determine which cue dominates directional selectivity. If MT neurons are unconcerned with sign of chromatic contrast, directional selectivity should be elicited by movement in the direction of the smallest spatial phase displacement, regardless of chromatic sign (in the chromatically "unsigned" direction; solid arrow in Fig. $1 B$ ), since spatial proximity is itself a potent determinant of motion correspondence (e.g., Ullman, 1980). If, on the other hand, the sign of chromatic contrast plays a significant role in motion detection, directional selectivity should be influenced most by movement in the direction that preserves chromatic sign (in the chromatically "signed" direction; dashed arrow in Fig. $1 B$ ).

\section{Method}

\section{Manipulation of luminance contrast in heterochromatic stimuli}

We employed a luminance bracketing procedure, in which we varied the relative luminances of the red and green phases of our heterochromatic gratings around the photometric red/green isoluminant point. By applying this procedure we felt confident that each neuron was presented with at least one red/green pair for which the two colors provided equally strong (or "balanced") inputs to the neuron. This red/green pair provisionally defined the neural isoluminance point. Red/green luminance contrast was thus varied across eight different levels ranging in equal intervals $(5.44 \%$ ) from $-24.2 \%$ (red brightest) to $+13.9 \%$ (green brightest). For one monkey (Lefty), the size of the luminance contrast interval varied somewhat (minimum interval $=6.2 \%$, maximum interval $=16.6 \%$ ) and luminance contrast ranged from $-54.9 \%$ to $+20.5 \%$.

\section{Manipulation of spatial displacement size}

In our moving contrast-reversed stimulus, the unsigned red/ green border is the most proximal cue for motion correspondence (Fig. I $B$, solid arrow). The size of spatial displacement for this border $(\Delta x$; Fig. $1 \mathrm{~B})$ was set between $10^{\circ}$ and $30^{\circ}$ phase angle $\left(0.057^{\circ}\right.$ to $0.17^{\circ}$ of visual angle). We chose to use these relatively small displacements because, in human psychophysical experiments, we have previously found them to produce a strong percept of motion in the unsigned direction at isoluminance (Dobkins and Albright, 1993).

Proximity has a pronounced and well-documented influence over motion correspondence (e.g., Ullman, 1980). It should therefore be possible to vary the impact of this proximity effect by adjusting the magnitude of the spatial phase displacement in the unsigned direction. (This manipulation is always accompanied, of course, by contrary changes in the signed direction.) For example, it should be possible to decrease the saliency of the unsigned border cue and increase the saliency of the signed border cue by increasing the size of the spatial displacement. To test this prediction, we collected data from a sample of MT neurons using spatial displacements of varying magnitudes.

\section{Achromatic control}

To determine whether small amounts of residual luminance contrast could account for the effects we observed using heterochromatic stimuli, we compared responses elicited by achromatic (yellow/black) contrast-reversed moving gratings (of varying luminance contrast) with those elicited under heterochromatic conditions. Four different achromatic luminance contrasts levels were used: $1.28 \%, 2.88 \%, 5.13 \%$, and $9.90 \%$.

\section{Results}

The basic phenomenon: effects of varving luminance contrast in heterochromatic stimuli

We tested 92 MT neurons with our heterochromatic contrastreversed moving stimulus. The principal result obtained from this manipulation is illustrated for one MT neuron in Figure 2. These data illustrate that, for a small range of luminance contrasts near photometric isoluminance, DI was significantly greater than zero, indicating that the neuron responded best to motion of the unsigned cue. By contrast, when luminance modulation exceeded $+5 \%$ or $-15 \%$, DIs became negative, indicating that, under these conditions, the neuron was more sensitive to motion of the signed cue

Because sign of luminance contrast is a key determinant of motion correspondence (e.g., Anstis, 1970; Anstis and Mather, 1985), we expect signed motion correspondence to be strongest (i.e., DIs most negative) at luminance extremes and weakest (i.e., DIs most positive) at isoluminance. To evaluate changes in DI as a function of luminance contrast, we fitted data from each neuron with a smooth curve by linearly interpolating between data points and convolving the interpolated curve with a gaussian $(\mathrm{SD}=2.3 \%)$. The red/green luminance contrast yielding the largest positive DI (the peak of this curve) was provisionally defined as the neural isoluminant point. This neural isoluminant point does not necessarily reflect "physical" isoluminance determined using a photometer. Moreover, since isoluminance can vary as a function of spatial (Mullen, 1985; Cavanagh et al., 1987; Logothetis and Charles, 1990) and temporal parameters (Cushman and Levinson, 1983; Kelly, 1983; Cavanagh et al., 1987; Swanson et al., 1988; Pokorny et al., 

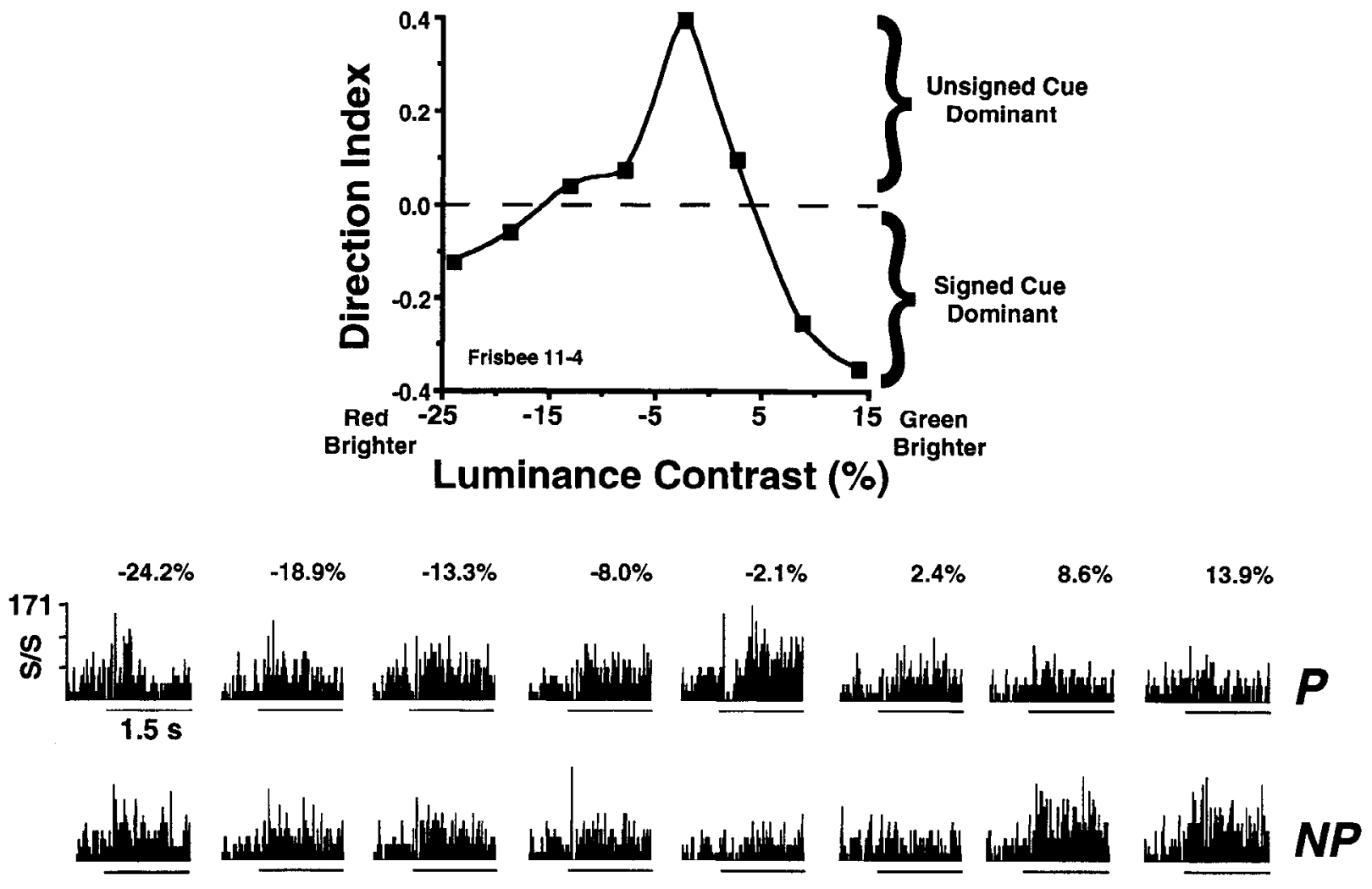

Figure 2. Evidence for a motion detection mechanism that disregards sign of chromatic contrast. This MT neuron was stimulated with the moving contrast-reversed stimulus, employed in Experiment I and depicted schematically in Figure $1 B\left(14.1^{\circ}\right.$ phase shift, $\left.30 \mathrm{frames} / \mathrm{sec}, 1.5 \mathrm{sec}\right)$. The neuron preferred motion down and to the right, and it exhibited a direction index (DI) of 0.30 when the stimulus consisted of a high contrast luminance-defined bar. Its receptive field was located in the upper contralateral quadrant, and centered $7.8^{\circ}$ eccentric to fixation. Luminance contrast between the red and green phases of the grating was varied across eight different levels ranging in equal $(5.44 \%)$ intervals from $-24.2 \%$ to $+13.9 \%$. Cumulative peristimulus histograms obtained in response to movement of the heterochromatic grating in the neuron's preferred (P) and nonpreferred (NP) directions are shown for each red/green luminance contrast level tested $(S / S=$ spikes $/ \mathrm{sec})$. We have arbitrarily defined $\mathrm{P}$ as responses elicited by motion of the unsigned border in the neuron's preferred direction. Likewise, NP responses are defined as those elicited by motion of the signed cue in the neuron's best direction. Direction indices $[\mathrm{DI}=(\mathrm{P}-\mathrm{NP}) /(\mathrm{P}+\mathrm{NP})]$, computed from responses elicited by motion in preferred $(P)$ and nonpreferred $(N P)$ directions, are plotted as a function of luminance contrast (above). For a small range of luminance contrast levels near photometric isoluminance, DIs were positive, suggesting that the neuron was responding to motion in the unsigned direction (Fig. $1 B$, solid arrow)-defying inversions of chromatic contrast. By contrast, when the absolute luminance modulation in these heterochromatic gratings exceeded $+5 \%$ or $-15 \%$, DIs became negative, suggesting that, under these conditions, the neuron was more sensitive to motion in the signed direction (Fig. $1 B$, dashed arrow). The (interpolated; see text) red/green luminance contrast yielding the largest positive DI was provisionally defined as the neural isoluminant point, which was determined to be $-2.46 \%$ for this neuron.

1989), this neural isoluminant point is defined only with respect to this particular stimulus condition.

Data from $83 / 92(90 \%)$ of the neurons in our sample could be characterized by an inverted $U$-shaped curve similar to that seen in Figure 2 (i.e., positive DIs near photometric isoluminance and negative DIs at luminance extremes). To obtain a measure of the population response for each animal, we averaged DIs across all neurons (Frisbee: $n=34$, Tutu: $n=33$, Lefty: $n=16$ ) for each of the eight luminance contrast levels tested (Fig. 3). As for single-neuron data, significant positive average DIs signify the use of borders defined by color without regard for the sign of chromatic contrast (i.e., unsigned motion correspondence). This occurred over a small range of luminance contrast levels near photometric isoluminance. Away from this point, average DIs were significantly negative, indicating that, as a population, MT neurons detected motion in the direction that preserved the sign of luminance and color correspondence (i.e., signed motion correspondence). Averaged DI data were fitted with a smooth curve as described above for single neuron data. For these stimulus conditions, average neural isolumi- nance points were determined to be $-2.32 \%$ (Frisbee), $-8.20 \%$ (Tutu), and $-2.56 \%$ (Lefty) luminance contrast.

Effects of stimulus speed. Due to the nature of our stimulus design, not only did signed and unsigned cues move in opposite directions, but the signed cue moved at a faster speed than the unsigned cue. The ratio of speeds is equal to the ratio of the phase angles of spatial displacement in the two opposing directions. Thus, if the unsigned phase angle were $20^{\circ}$ (and the signed were thus $160^{\circ}$ ), the unsigned cue would move at $3.3 \% \mathrm{sec}$ and the signed cue would move at $26.8 \% \mathrm{sec}$ - an eightfold difference in speed. It is reasonable to infer, however, that MT neurons were capable of detecting motion at both speeds as evidenced by the finding of both positive and negative DIs for single neuron (Fig. 2) and population (Fig. 3) data. It seems likely, nonetheless, that most neurons have some differential sensitivity to the two speeds used (Maunsell and Van Essen, 1983a; Rodman and Albright, 1987). For this reason we have refrained from an attempt to estimate the relative strengths of signed versus unsigned cues.

It is also possible that the presence of both signed and un- 

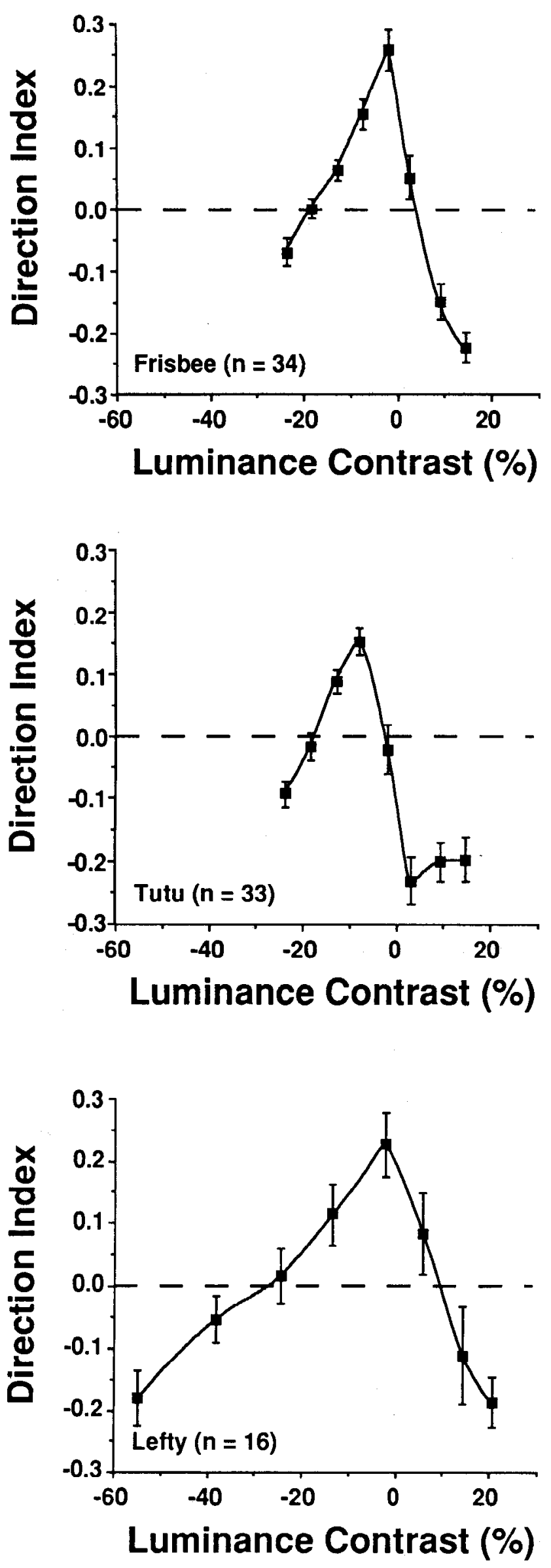

signed cues moving in opposite directions was mutually antagonistic, thereby attenuating the strength of neural response to each. This could explain the relatively low DIs observed (Figs. 2,3 ), a result that is consistent with previous experiments demonstrating diminished MT responses to stimuli composed of two random dot surfaces superimposed and moving in opposite directions (Snowden et al., 1991). Unlike the stimuli in these earlier studies, however, our stimulus does not lead to a percept of two simultaneous (transparent) motions; only signed or unsigned motion is perceived.

\section{Influence of spatial displacement magnitude}

In order to examine the effects of spatial displacement magnitude, we collected data from 14 MT neurons using multiple spatial displacement magnitudes. Data obtained from one neuron are shown in Figure 4. Motion was produced by repetitive displacement of the unsigned border by each of two different spatial phase angles: $20^{\circ}$ and $30^{\circ}$ (equivalent to $0.11^{\circ}$ and $0.17^{\circ}$ of visual angle, respectively). Both displacements produced characteristic inverted U-shaped curves. The larger spatial displacement, however, yielded a shift towards more negative DI values and an increase in the peakedness of the curve. Similar transformations were observed for all 14 neurons tested in this manner. Changes of this sort are precisely what one would predict as a consequence of decreasing the potency of the unsigned cue. Furthermore, it can be seen that for the larger spatial displacement, less luminance contrast was needed to favor a signed mechanism. These results imply that the use of signed versus unsigned cues for motion correspondence is influenced by spatial displacement in combination with luminance contrast.

\section{Chromatic contrast or low levels of luminance contrast?}

Cavanagh et al. (1984) reported that the perceived speed of moving heterochromatic gratings was markedly slowed at chromatic isoluminance (relative to that of heterochromatic gratings containing high levels of luminance contrast). The relevance of chromatic contrast to this perceived slowing might be called into question, however, becausc motion of achromatic gratings also appears slowed if luminance contrast is sufficiently low (Thompson, 1982). Reinforcing the argument that it is the presence of chromatic contrast - and not simply low levels of luminance contrast - that underlies the perceived slowing of heterochromatic gratings at isoluminance, it can also be shown that the perceived speed of a low contrast achromatic grating can be reduced simply by adding color to it (Cavanagh et al., 1984).

In a similar vein, we entertained the possibility that the tendency for MT neurons to signal motion in the unsigned direction near isoluminance was due to the absence of sufficiently high levels of luminance contrast in our heterochromatic gratings

Figure 3. Indices of directional selectivity averaged across MT neurons presented with chromatic contrast-reversed stimuli (Experiment I). Average DI is plotted as a function of heterochromatic luminance contrast for each of three monkeys. Error bars denote SEMs. The average data for each of the three monkeys exhibited inverted U-shaped curves with significant positive and significant negative DIs. Significant positive DIs signify the use of borders defined by color without regard for the colors themselves (i.e., unsigned motion correspondence). This occurs over a range of luminance contrast levels near the photometric isoluminance point. At luminance extremes, DIs were negative, indicating that the neurons were more sensitive to motion in the direction that preserved luminance and chromatic sign. 


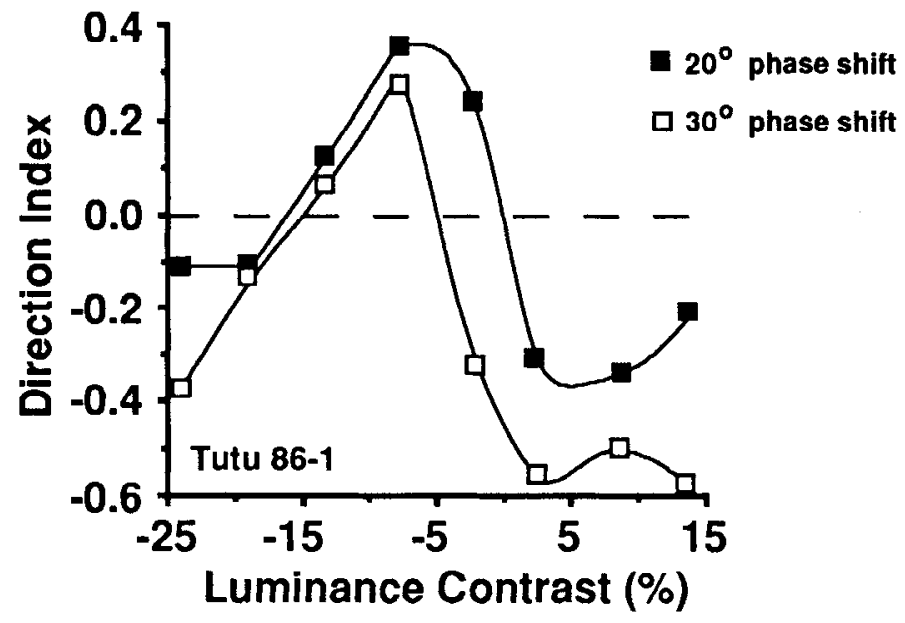

Figure 4. Effects of spatial displacement magnitude studied in Experiment I. This neuron preferred upward motion and it exhibited a direction index of 0.79 when the stimulus consisted of a high contrast luminance-defined bar. Its receptive field was located in the upper contralateral quadrant and centered $9.8^{\circ}$ eccentric to fixation. Responses elicited by the heterochromatic contrast-reversing stimulus moving in preferred $(P)$ and nonpreferred $(N P)$ directions are shown for two different spatial displacements, $20^{\circ}(A)$ and $30^{\circ}(B)$ phase shift. DIs obtained from this manipulation are plotted as a function of heterochromatic luminance contrast (above). Both displacements produced characteristic inverted $U$-shaped curves. The larger spatial displacement $\left(30^{\circ}\right.$ phase shift), however, yielded an overall shift towards more negative DI values and an increase in the peakedness of the curve. Furthermore, for the larger phase shift $\left(30^{\circ}\right)$, less luminance contrast was needed in order to favor a signed mechanism. These results imply that the use of signed versus unsigned cues for motion correspondence is influenced by spatial displacement in combination with luminance contrast.
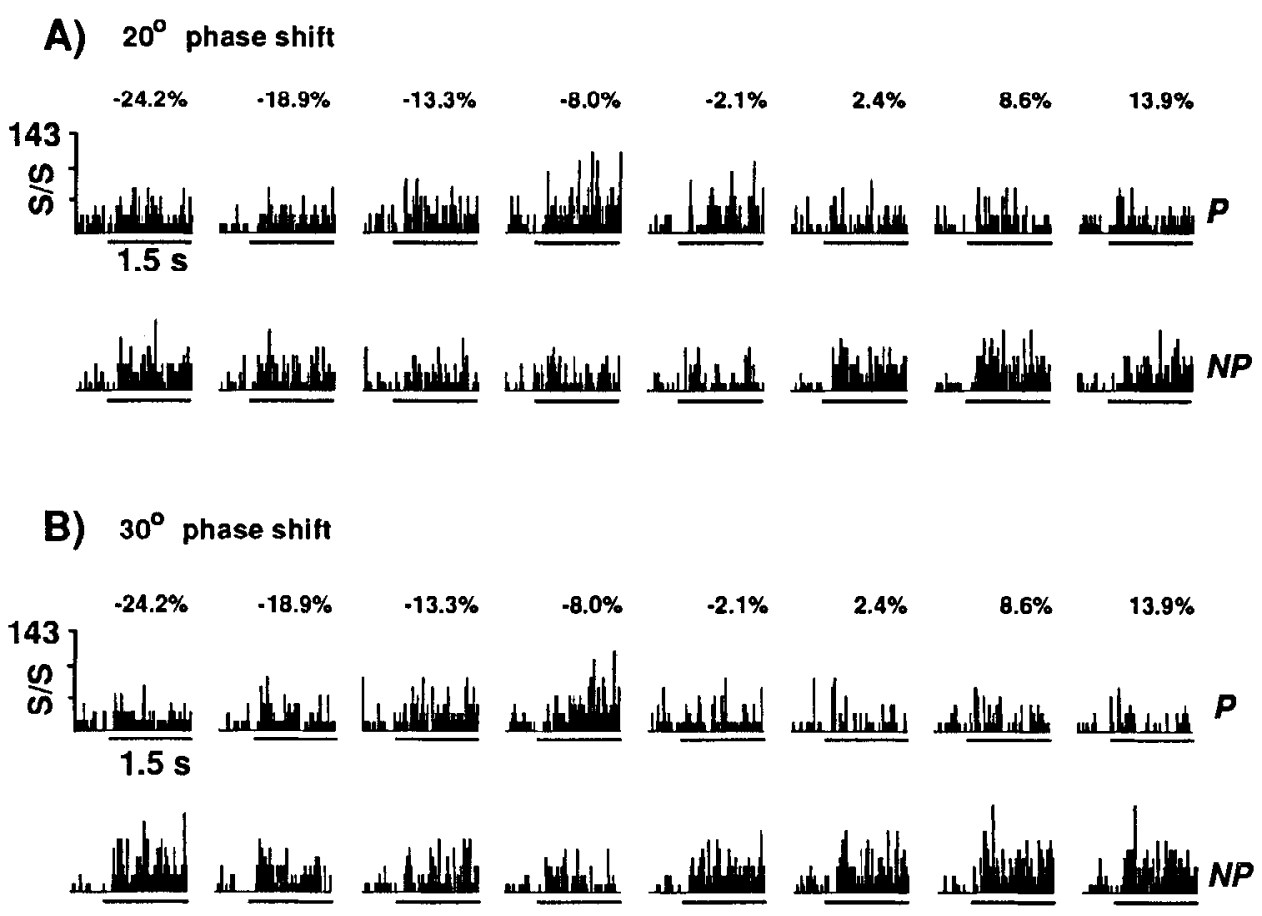

and not due to the presence of chromatic contrast per se. To test this possibility, we collected data using achromatic (yellow/ black) gratings that underwent reversal of luminance contrast sign with each spatial displacement. These stimuli were identical in all respects to our heterochromatic gratings, save the absence of chromatic contrast. Illustrative results from one neuron are shown in Figure 5. Under heterochromatic conditions (Fig. 5A), this neuron exhibited the characteristic inverted U-shaped DI curve (cf. Fig. 3). When the same neuron was presented with achromatic gratings (Fig. $5 B$ ), however, responses to motion of the signed cue (NP, by our convention) were always larger than responses to motion of the unsigned cue ( $\mathrm{P}$, by our convention). Thus, DIs were negative at all luminance contrast levels tested. In other words, under achromatic conditions, the neuron responded to motion in the direction for which sign of luminance contrast was preserved. Furthermorc, the fact that positive DIs were seen only for the heterochromatic case (Fig. $5 A$ ) but not for the achromatic case (Fig. $5 B$ ) suggests that the simple addition of chromatic contrast led to a reversal of the DI.
To obtain a measure of the population response, we averaged DIs across all neurons ( $n=75$, two monkeys) for each of the four luminance contrast levels tested. As for single-neuron data (Fig. $5 B$ ), averaged responses elicited by signed luminance cues were always larger than those elicited by unsigned luminance cues.

\section{Experiment II: $90^{\circ}$ (“ambiguous”) phase displacement}

In Experiment I we used spatial displacements corresponding to small phase offsets in order to reveal the existence of an unsigned chromatic mechanism. The results of these experiments demonstrated that the vast majority of $\mathrm{MT}$ neurons were able to detect motion of borders defined by chromatic contrast without regard for the chromatic sign. Having previously found that sign of chromatic contrast can carry motion correspondence in human observers (Dobkins and Albright, 1993), however, we sought to determine whether there exist conditions under which chromatic sign has a corresponding influence over directionally 
A)

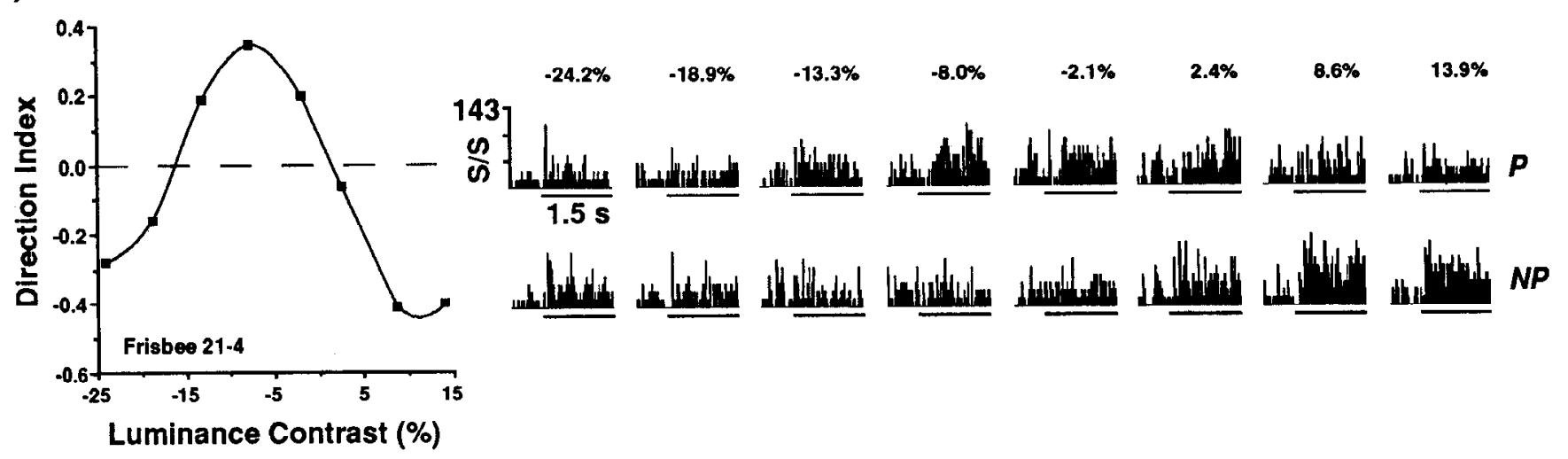

B)

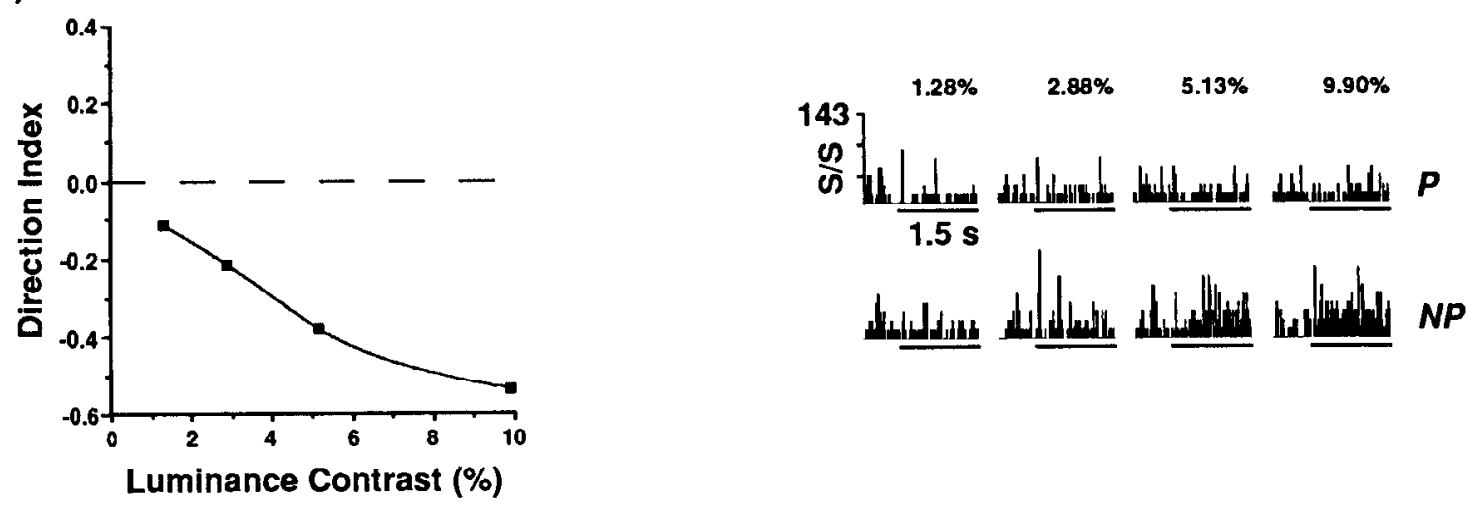

Figure 5. Comparison of the effects of heterochromatic and achromatic contrast-reversed moving gratings used in Experiment I. This MT neuron preferred upward motion and exhibited a direction index of 0.35 when tested with a high contrast luminance-defined bar. Its receptive field was centered on the vertical meridian, $6^{\circ}$ above the center of gaze. $A$, Heterochromatic gratings. DI is plotted as a function of red/green luminance contrast. This neuron exhibited a typical inverted $U$-shaped curve, containing both positive and negative DI values. (P and NP responses are shown to the right.) $B$, Achromatic gratings. These stimuli were identical in all respects, save the absence of chromatic contrast, to our heterochromatic gratings. Four different luminance contrasts levels were used: $1.28 \%, 2.88 \%, 5.13 \%$, and $9.90 \%$. Responses elicited by motion of the signed cue (NP, by our convention) were always larger than responses elicited by motion of the unsigned cue ( $\mathrm{P}$, by our convention). This resulted in negative DIs for all luminance contrast levels tested. Thus, the neuron always detected motion in the direction that preserved the sign of luminance contrast. The fact that this neuron exhibited large positive DIs when presented with heterochromatic, but not achromatic, gratings demonstrates that the tendency to signal motion in the unsigned direction is attributable to the presence of chromatic variation in these stimuli.

selective responses in MT. To address this issue directly, we conducted a second experiment (Experiment II) using heterochromatic sine wave gratings undergoing repetitive $90^{\circ}$ phase displacements. This $90^{\circ}$ condition is singular among all possible phase displacements owing to the fact that unsigned cues permit no unique estimation of direction of motion (Fig. $1 C$ ). If MT neurons continue to signal direction of motion under these conditions it necessarily results from a mechanism that relies upon chromatic sign.

\section{Method}

The spatial properties of the stimuli used in Expcriment II were identical to those used in Experiment I except for the difference in size of spatial displacement and the use of finer luminance contrast intervals. The use of relatively large luminance contrast intervals with heterochromatic stimuli (5.44\%, employed in Experiment I) allows for the possibility that a neuron's isoluminant point may be missed by as much as, but no more than, $2.72 \%$ (the mismeasure that would occur if the neural isoluminant point were to fall directly in the middle of a luminance contrast interval). Because many MT neurons are exquisitely sensitive to achromatic luminance contrast, maintaining significant di- rectional selectivity for stimuli below $2 \%$ contrast (Saito et al., 1989; Sclar et al., 1990), it seems likely that some neurons will also respond to moving heterochromatic gratings possessing $2.72 \%$ luminance contrast. Under such conditions it would be difficult to draw reliable conclusions about the contribution of chromatic sign to directional selectivity.

To address this concern, we first tested each MT neuron using coarse (5.44\%) luminance contrast intervals (same luminance contrast range and interval employed in Experiment I). A smooth curve was then fitted to the DI data, and the luminance contrast yielding the minimum in the curve was determined. Each neuron was then retested using fincr luminance contrast intervals $(1.37 \%)$ centered on the minimum obtained from the coarse interval manipulation. Using $1.37 \%$ intervals, residual luminance contrast could have been as much as, but no more than, $0.685 \%$. This "worst case" value is below threshold for nearly all MT neurons (Saito et al., 1989; Sclar et al., 1990).

The isoluminant point for each neuron was provisionally defined as the luminance contrast that yielded the minimum DI in the finer interval condition. Due to differences in stimulus configuration, "isoluminance" is differentially defined in Experiments I (curve maximum) and II (curve minimum). Each 

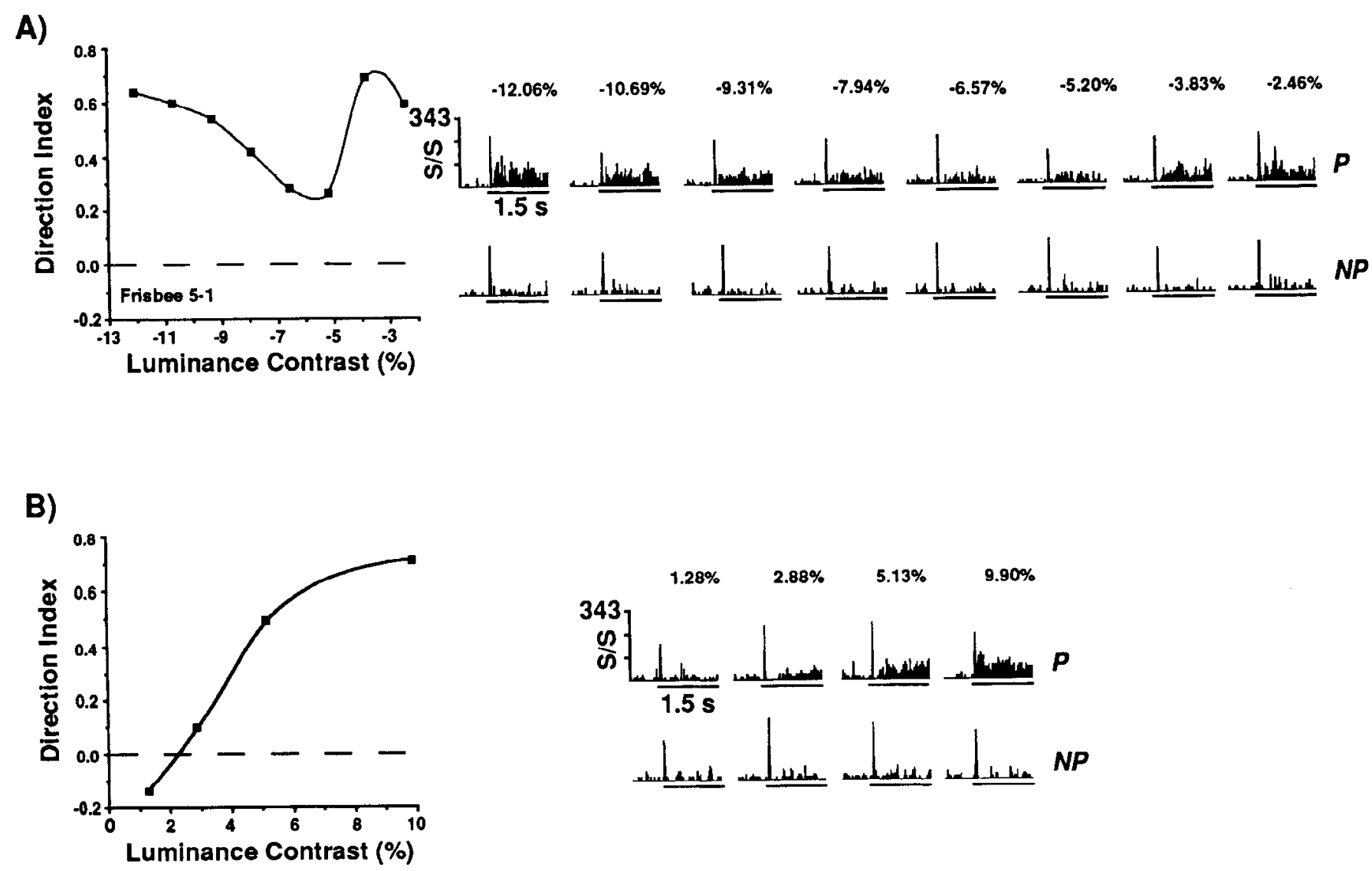

Figure 6. Comparison of the effects of heterochromatic and achromatic $90^{\circ}$ phase-shifted gratings used in Experiment II. This MT neuron preferred motion to the left and exhibited a direction index of 0.80 when tested with a high contrast luminance-defined bar. Its receptive field center was located in the upper contralateral quadrant, $8.5^{\circ}$ eccentric to fixation. $A$, Heterochromatic gratings. Responses elicited by movement of the stimulus in the neuron's preferred and nonpreferred directions are shown for eight different luminance contrast levels, ranging in equal "fine" intervals (1.37\%) from $-12.06 \%$ to $-2.46 \%$. The minimum DI elicited by this neuron was $33 \%$ of that obtained when the grating contained saturating levels of luminance contrast. $B$, Achromatic gratings. Responses and resulting DIs obtained from the same neuron using achromatic stimuli are shown for four different luminance contrast levels $(1.28 \%, 2.88 \%, 5.13 \%$, and $9.90 \%)$. DIs for this neuron reached ceiling levels near $10 \%$ contrast. The negative index generated for the lowest luminance contrast level tested (1.28\%) is not a general characteristic of the population of neurons sampled; on average, neurons exhibited a small but significant positive DI at this contrast level (see Fig. 7).

definition represents a neurally defined isoluminant point for the specific stimulus condition employed.

\section{Results}

The basic phenomenon: responses to $90^{\circ}$ phase displacement of heterochromatic stimuli

We tested a sample of 141 MT neurons using heterochromatic sine wave gratings undergoing repetitive $90^{\circ}$ phase displacements. (A subset of these neurons was also tested under the conditions of Experiment I.) For each neuron, luminance contrast was initially varied using coarse luminance contrast intervals $(5.44 \%)$. The finer interval manipulation (1.37\%) was then performed on a subset of this sample ( $n=88$, two monkeys).

Eighty-three of $88(94 \%)$ neurons exhibited DIs that remained positive for all luminance contrast levels tested in the fine interval condition. These results strongly suggest that sign of chromatic contrast can be used to elicit directional selectivity in MT neurons. Nonetheless, 79 of $88(90 \%)$ neurons exhibited a clear minimum DI within the range of the eight luminance contrast levels tested. An illustrative example is presented in Figure $6 \mathrm{~A}$. This neuron exhibited a minimum in the DI curve at $-5.72 \%$ luminance contrast, which was provisionally defined as the neuron's isoluminant point for this stimulus condition. At this min- imum, DI was approximately $33 \%$ of that obtainable when saturating levels of luminance contrast were added to the heterochromatic stimulus. Averaging across MT neurons, this minimum DI, expressed as a fraction of the maximum DI obtainable, was $53.2 \%$ for one monkey (Frisbee, $n=45$ ) and $28.5 \%$ for the other monkey (Tutu, $n=34$ ). The existence of these minima confirms previous reports that MT responses are compromised when moving stimuli are defined solely by chromatic contrast (Charles and Logothetis, 1989; Saito et al., 1989; Movshon et al., 1991; Gegenfurtner et al., 1994), supporting the notion that chromatic cues have limited influence over motion correspondence. Nonetheless, despite an overall reduction in directional selectivity at isoluminance, these data demonstrate that chromatic sign is sufficient for establishing motion correspondence.

\section{Directional selectivity elicited by chromatic versus achromatic $90^{\circ}$ phase displacement}

To further assess whether residual luminance contrast could account for directionally selective responses observed using heterochromatic gratings, we compared data acquired using such stimuli to data acquired using achromatic gratings. Each neuron $(n=88)$ that was tested with the fine heterochromatic luminance 
contrast intervals (1.37\%) was also tested using achromatic (yellow/black) gratings at four different luminance contrast levels $(1.28 \%, 2.88 \%, 5.13 \%$, and $9.90 \%)$. Representative results are shown in Figure $6 B$. Achromatic stimuli possessing either $1.28 \%$ or $2.88 \%$ contrast elicited DIs that fell well below any DI derived from the heterochromatic condition (cf. Fig. $6 A$ ). On the basis of these data, we conclude it highly unlikely that small levels of residual luminance contrast (had they existed) could account for the results obtained from this neuron using heterochromatic stimuli.

Population-averaged DI curves are presented separately for two animals (Tutu and Frisbee) in Figure 7. The achromatic data demonstrate that MT neurons are highly sensitive to luminance contrast, with directional selectivity reaching ceiling levels at about $10 \%$ contrast, in accordance with previous results (Saito et al., 1989; Sclar et al., 1990). Under heterochromatic conditions, we found chromatic contrast to be clearly beneficial in the limiting case of isoluminance as evidenced by average DIs that remain significantly above zero (midpoint along each of the $x$-axes in Fig. 7). These data indicate that an isoluminant heterochromatic grating elicits an average DI value that is approximately equivalent to that clicitcd by a $2.5 \%$ contrast achromatic grating. This value represents the "equivalent luminance contrast" of red/green isoluminant stimuli for MT neurons (cf. Cavanagh and Anstis, 1991; Agonie and Gorea, 1993). Because this value greatly exceeds the maximum residual luminance contrast that could have existed due to undersampling of luminance contrast levels (see above), we feel confident that residual luminance contrast cannol account for results obtained under heterochromatic conditions.

In addition to confirming the potency of moving stimuli defined solely by chromatic variation, the DI curves in Figure 7 enabled us to examine what, if any, benefit chromatic contrast confers when moving stimuli also possess luminance modulation. Comparison of DIs elicited by heterochromatic versus achromatic stimuli possessing identical levels of luminance contrast indicate that, for stimuli with relatively low levels of luminance contrast, the addition of chromatic information markedly improves the ability of MT neurons to discriminate direction of motion. At larger luminance contrasts (greater than about $4 \%$ ), however, the heterochromatic and achromatic curves converge, suggesting that there is little to be gained from color, provided that luminance contrast is sufficiently large.

\section{Relative responsivity to color-versus luminance-defined stimuli: color/luminance ratios}

Thus far, the majority of our data have been presented in the form of a derived measure of directional selectivity, i.e., a direction index. We chose this metric over response magnitude in the preferred direction because we believe that the former more closely represents the neural "population" response (i.e., a given stimulus will simultaneously move in the preferred direction for some neurons and in the nonpreferred direction for others). For statistical reasons, however, DI is an unsuitable metric for computing an index of the relative effectiveness of color-defined versus luminance-defined stimuli. For this purpose, therefore, we employed a more direct measure: response (spikes/second) elicited by motion in the neuron's preferred direction.

Our analysis was performed using data obtained from the heterochromatic ( $1.37 \%$ intcrval manipulation) and achromatic conditions of Experiment II. For each neuron sampled, we di-
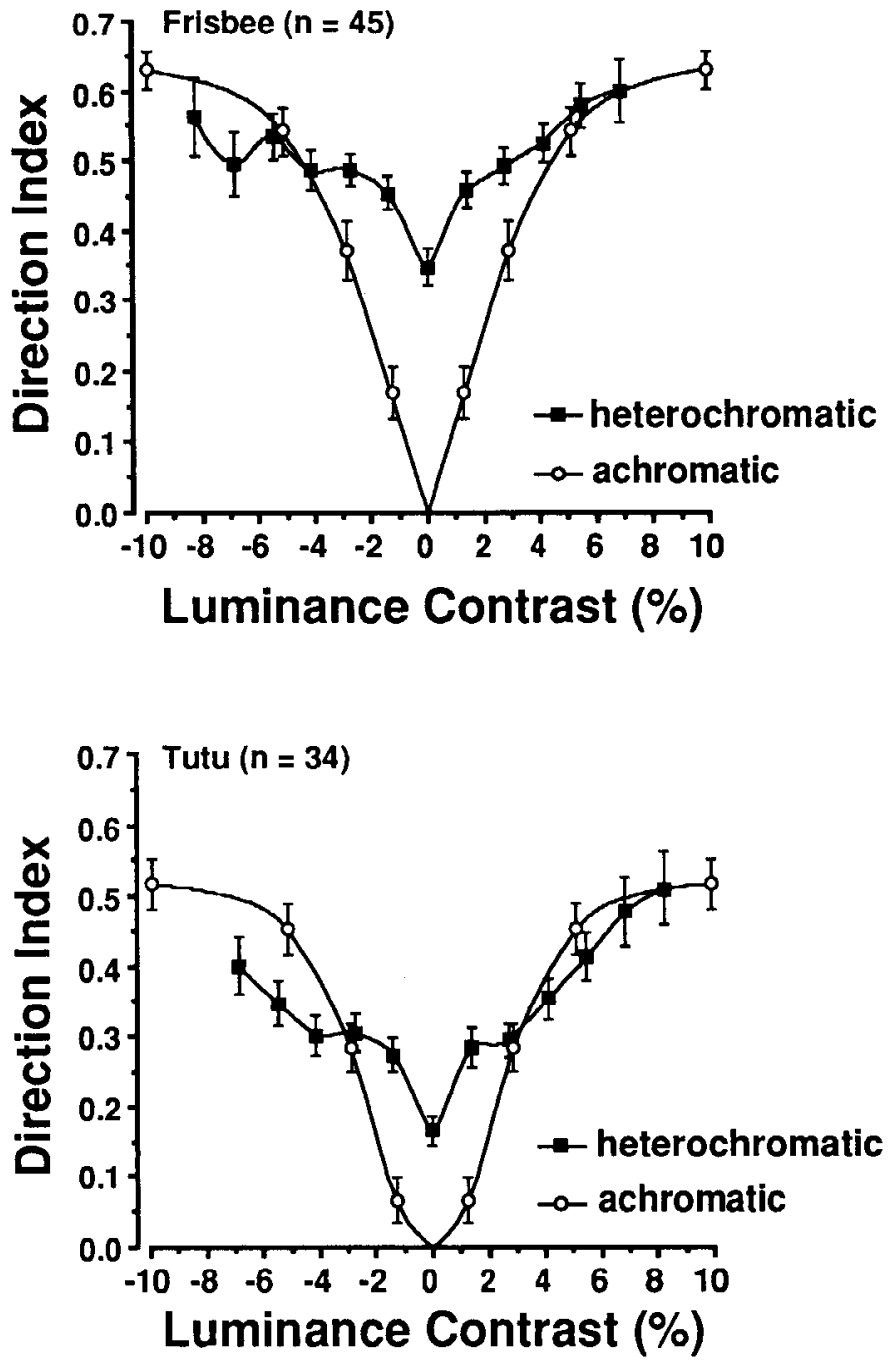

Figure 7. Relative efficacy of luminance and chromatic contrast as cues for motion correspondence. Indices of directional selectivity have been averaged across MT neurons studied with heterochromatic and achromatic $90^{\circ}$ phase-shifted gratings used in Experiment II. Data are shown separately for two monkeys. For heterochromatic data (solid squares), the red/green luminance contrast yielding the minimum DI (the "neural" isoluminant point) varied from neuron to neuron. For this analysis, we were interested in evaluating changes in DI as a function of luminance contrast, not the contrasts yielding the minimum DI value. Therefore, the minima in the individual DI curves were aligned with one another before averaging across the sample. Luminance contrast values for the heterochromatic condition therefore reflect "relative" luminance contrast ( $0 \%$ denoting the isoluminant point for each neuron) and do not correspond to the actual physical luminance contrast present in the stimulus. [Although each neuron was tested with eight different heterochromatic luminance contrasts over a $10 \%$ range, the averaged data across neurons spans a broader range. This is due to the fact that individual minimums in the DI curves did not always coincide with the center of the luminance contrast range tested. As a consequence of this alignment procedure, therefore, $0 \%$ luminance contrast contains data from all neurons, whereas the number of neurons averaged into the other luminance contrast points decreases with distance from $0 \%$ (hence, higher SEs at the extremes).] Data obtained using achromatic stimuli (open circles) have been reflected around the $0 \%$ luminance contrast point to facilitate comparison with the heterochromatic data. Luminance contrast values reflect actual contrast in the achromatic stimulus. The addition of chromatic contrast improves directional selectivity when luminance contrast is low, but confers no such benefit at higher (greater than about $4 \%$ ) luminance contrast levels. 


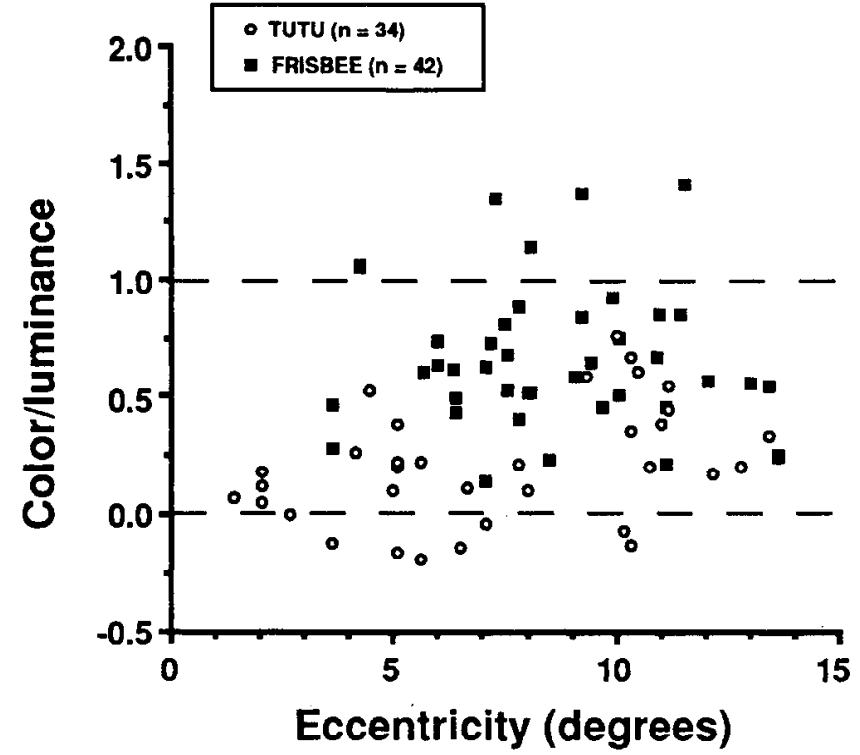

Figure 8. Relative strength of color- versus luminance-facilitated motion correspondence as a function of receptive field center eccentricity. Data are shown for two monkeys. The minimum response (spikes/ second) elicited from each neuron using red/green $90^{\circ}$ phase-shifted gratings was divided by the response (spikes/second) elicited by achromatic gratings containing near saturating levels $(10 \%)$ of luminance contrast. The resulting ratio represents the response elicited by a chrominance-defined pattern as a fraction of that elicited by a luminancedefined pattern. A ratio below 1.0 indicates that the response elicited by chromatic contrast was weaker than that clicited by saturating levels of achromatic luminance contrast. Conversely, a ratio greater than 1.0 indicates that chromatic contrast was more effective than achromatic luminance contrast. [Negative ratios (obtained from seven neurons) were generated when the response obtained using the heterochromatic stimulus was negative (below baseline).] The lack of any significant correlation between these color/luminance ratios as a function of receptive field eccentricity implies that, with respect to responses in $\mathrm{MT}$, the central visual field is not more specialized for color than it is for luminance processing.

vided the smallest response obtained using heterochromatic gratings by the response obtained using achromatic stimuli possessing near saturating levels $(10 \%)$ of luminance contrast. This ratio represents the response elicited by a moving stimulus defined by color as a fraction of that elicited by a stimulus defined by luminance.

With few exceptions, color/luminance ratios fell below 1.0 , suggesting that, as a general rule, luminance could be used more effectively than color for eliciting MT responses. On average, color/luminance ratios were 0.65 (Frisbee, $n=42$ ) and 0.21 (Tutu, $n=34$ ). It has been argued that the relative effectiveness of heterochromatic (red/green) and achromatic (yellow/black) stimuli should be expressed with respect to the root mean squared (r.m.s.) contrast produced in the L and M cones (e.g., Stromeyer, 1990). In this context, it is interesting to note that our data indicate that chrominance is markedly less effective than luminance, despite the fact that our chrominance-defined stimuli produce a higher r.m.s. cone contrast $(\sim 26 \%)$ than our luminance-defined stimuli $(\sim 10 \%)$.

Color/luminance ratios as a function of eccentricity. Receptive field centers of our sampled MT neurons ranged from $1^{\circ}$ to $14^{\circ}$ eccentric to the center of gaze, affording us the opportunity to investigate whether responses elicited by chrominance-defined gratings decrease more rapidly with eccentricity than do those elicited by luminance-defined stimuli.

Relevant comparisons were made for two monkeys (Tutu and Frisbee) using the derived color/luminance ratios described above. If, as some psychophysical data suggest (Mullen, 1991), the central visual field is relatively more specialized for color than for luminance processing, we might expect this ratio to decline with increasing eccentricity. Results are shown in Figure 8. For neither monkey did we observe a significant correlation between receptive field eccentricity and the relative strength of response elicited by chromatic versus luminance contrast. These results are in accordance with previous results demonstrating that the decrements in MT responses to pure color contours do not vary systematically with eccentricity (Saito et al., 1989). With respect to the relative effectiveness of chrominance versus luminance as a function of eccentricity, therefore, neurophysiological data from MT (Saito et al., 1989, and those reported herein) apparently contradict psychophysical results (Mullen, 1991).

\section{General Discussion}

We have presented evidence demonstrating that motion processing in extrastriate visual area MT exploits one of the most salient features of our visual world, namely, color. Our results, moreover, have two key implications concerning the types of chromatic information used by MT neurons. First, under some conditions these neurons appear to be capable of using information about chromatically defined image contours while ignoring information about chromatic sign. Second, when unsigned borders provide only ambiguous information about direction of motion, chromatic sign can be shown to be sufficient for motion detection by MT neurons. In the real world, of course, chromatically defined image contours and the specific colors that define those contours typically move as one, which leads us to conclude that neural mechanisms underlying the use of unsigned and signed cues normally work in unison.

We have shown that the signed and unsigned mechanisms in area $\mathrm{MT}$ can be isolated by appropriate visual stimulation and, moreover, that their relative strengths vary as a function of luminance contrast and spatial displacement. The results of these manipulations shed light on the neural mechanisms involved, and permit some speculation about the relative contributions of magnocellular and parvocellular pathways to motion detection. Before proceeding, however, we will first evaluate potential confounding factors and attempt to discount the possibility that they have contributed to the observed effects.

\section{Potential confounding factors: effects of chromatic aberration, rod contribution, and retinal inhomogeneities}

Chromatic aberration. Longitudinal chromatic aberration is a potentially significant source of luminance contamination in heterochromatic stimuli. The "dominant" frequencies of the red $(620 \mathrm{~nm})$ and green $(545 \mathrm{~nm})$ phosphors in our stimuli differ by about 0.4 diopters in the human eye (Howarth and Bradley, 1986). Although differential diffraction of this magnitude is potentially troublesome, the effective luminance contrast introduced by chromatic aberration is markedly dependent upon spatial frequency and is minimal $(<0.5 \%$ for maximum $4 \mathrm{~mm}$ pupil) for the 0.49 cycle/degree sinusoidal heterochromatic gratings used in our experiments (Flitcroft, 1989; Cavanagh and Anstis, 1991). Potential abcrration-induced contrast is therefore below psychophysical detection threshold (Robson, 1966; Lo- 
gothetis, 1990; Cavanagh and Anstis, 1991) and below the sensitivity of MT neurons (Saito et al., 1989; Sclar et al., 1990).

Contribution from rod photoreceptors. The average luminance of our display $\left(8.1 \mathrm{~cd} / \mathrm{m}^{2}\right)$ is beneath that needed to saturate human rods (Aguilar and Stiles, 1954). It is therefore probable that the red and green phascs of our hetcrochromatic gratings differentially activate rod photoreceptors. Differential rod activation could, in principle, contribute to neuronal directional selectivity elicited by heterochromatic stimuli balanced for $\mathrm{L}$ and $M$ cone activation. While we cannot entirely rule out this possibility, we deem it unlikely because we have previously shown (Dobkins and Albright, 1993), using stimuli that were identical to those employed in the present study, that chromatic contrast remains a sufficient cue for motion discrimination by human subjects when rods have been rendered nonfunctional (during the cone plateau period that follows a rod bleach). This argument is further strengthened by the observed effects of achromatic luminance contrast in Experiment I (Fig. 5B). Specifically, we would expect the presence of a residual luminance signal (resulting from rod intrusion) to contribute to signed motion correspondence. This prediction, however, is directly opposed to the unsigned peak that we consistently observed under heterochromatic conditions (Fig. 5A).

Spatial variations in chromatic sensitivity. Variations in the relative sensitivity to red and green light as a function of visual field eccentricity is another avenue by which isoluminant stimuli might generate residual luminance signals within the neural pathway. Although the macular pigment (which decreases rapidly from $0^{\circ}$ to $3^{\circ}$ eccentricity) absorbs wavelengths differentially, it is thought to have a negligible effect on the relative sensitivities of the $M$ and $L$ cones (Wooten et al., 1975; Stabell and Stabell, 1980, 1981; Viénot, 1980). Moreover, the receptive fields of most neurons in our sample were too eccentric to include the macula. It is also possible that spatial variations in M:L cone ratios could lead to differential sensitivity to red and green light. Despite this possibility, there exists substantial consensus [but not without exception (Livingstone and Hubel, $1987 \mathrm{~b})$ ] from a variety of studies that the relative contributions of $\mathrm{M}$ and $\mathrm{L}$ cones do not vary with eccentricity (Wooten and Wald, 1973; Wooten et al., 1975; Marc and Sperling, 1977; Stabell and Stabell, 1980, 1981; Noorlander et al., 1983; van Esch et al., 1984; Mullen, 1991; Nerger and Cicerone, 1992). Furthermore, previous experiments conducted in area MT have shown that neuronal responses to moving isoluminant stimuli cannot be explained by regional cone or pigmental variations (Saito et al., 1989). Finally, we found that, while the neural isoluminant point varied from neuron to neuron, there was no systematic relationship between these red/green balance points and eccentricity (K. R. Dobkins and T. D. Albright, unpublished observations). On these various grounds we think it unlikely that spatial variations in sensitivity to the red and green components of our stimuli can account for our results.

\section{Luminance and color as cues for motion correspondence}

In Experiment I, we found that for a small range of luminance contrasts near photometric isoluminance, MT neurons responded to motion in the direction of the nearest chromatically defined border, despite ongoing inversions of chromatic contrast at that border. By contrast, away from photometric isoluminance, MT neurons responded best to motion in the direction that preserved luminance and chromatic sign. Thus, when luminance contrast is sufficiently high, luminance sign (in conjunction with chro- matic sign) is a stronger determinant of motion correspondence than unsigned chromatic (and luminance) contrast, despite the fact that proximity favors the latter. The influence of luminance is further revealed by the results we obtained using achromatic gratings that underwent contrast sign reversal with each spatial displacement: responses elicited by motion of the signed luminance cue were always larger than those elicited by motion of the proximal unsigned cue. These results demonstrate that motion correspondence in MT is strongly influenced by polarity of luminance contrast, and they parallel what has previously been found in human psychophysical experiments (Anstis, 1970; Dobkins and Albright, 1993). Moreover, since the observed unsigned peak for heterochromatic gratings was generally broad enough to encompass a substantial range of luminance contrasts (Fig. 3), it can be stated that the addition of chromatic modulation to a low contrast achromatic grating is sufficient to cause a reversal of directional selectivity (e.g., Fig. 5). These results discredit the possibility that low luminance contrast alone is sufficient to explain the unsigned peak, and they further imply that unsigned chromatic contrast is a relatively strong cue for motion correspondence.

In Experiment II ( $90^{\circ}$ phase displacement), we found that signed chromatic contrast was sufficient for eliciting directional selectivity, although, on average, DIs were markedly compromised. We also found that, on average, chromatic contrast improves the ability of MT neurons to discriminate direction of motion for gratings possessing low levels of luminance modulation (Fig. 7). At larger luminance contrasts (greater than 3 $5 \%$ ), however, hetcrochromatic and achromatic stimuli clicit comparable directional selectivity, suggesting that there is little to be gained from color when luminance contrast is sufficiently high.

\section{Relation to psychophysical demonstrations of color-facilitated motion correspondence}

In human psychophysical experiments (Dobkins and Albright, 1993) employing stimuli nearly identical to those used in the present study, we found that perceived direction of motion could be modulated by the same manipulations that we have now found to influence MT neurons. Averaged behavioral responses from three human psychophysical observers are shown in Figure 9. These subjects viewed the red/green contrast-reversing stimulus (used in Experiment $I$ and illustrated in Fig. $1 B$ ) at varying levels of luminance contrast. The observed relationship between perceived direction of motion and luminance contrast is strikingly similar to that seen for neuronal directional selectivity in MT (e.g., Fig. 3). We found, furthermore, that increasing the size of spatial phase displacement had corresponding perceptual and neuronal effects, that is, relative impairment of an unsigned motion correspondence mechanism (cf. Figs. 4, 9).

Finally, when human observers viewed the $90^{\circ}$ phase-shifted stimulus (used in Experiment II and illustrated in Fig. $1 C$ ), they reported motion in the direction that preserved chromatic sign (see Fig. 8 of Dobkins and Albright, 1993), a result that is consistent with other psychophysical data (Green, 1989; Papathomas et al., 1989, 1991; Gorea and Papathomas, 1989; Dobkins and Albright, 1990; Gorea et al., 1990), and concordant with the behavior of MT neurons under these conditions (Fig. 7).

Despite these strong indications of a parallel relationship between neuronal activity and perception, other recent expcriments suggest that MT cannot account for perceived motion of 


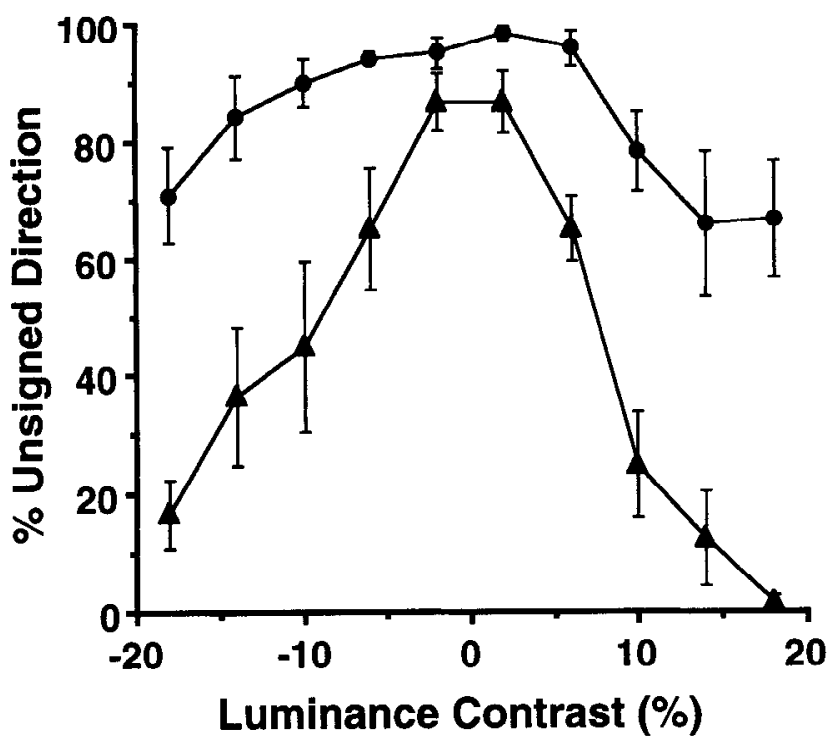

$\longrightarrow 12.9^{\circ}$ phase shift

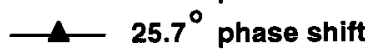

Figure 9. Psychophysical assessment of perceived direction obtained from human subjects viewing the red/green contrast-reversed moving stimulus (employed in Experiment I of the present study and illustrated in Fig. $1 B$ ). Similar to our neurophysiological experiments, red/green luminance contrast was varied across 10 different levels ranging in equal (4\%) intervals from $-18 \%$ (red brightest) to $+18 \%$ (green brightest). Reports of perceived direction have been averaged over three subjects ( 40 trials/luminance contrast/subject). Averaged data have been plotted as percent "unsigned direction" responses for two different spatial phase shifts (comparable to those used in Experiment I of the present study; see Fig. 4 ), $12.9^{\circ}$ (circles) and $25.7^{\circ}$ (triangles). This percentage identifies the fraction of trials for which subjects reported motion in the direction of the contrast-reversing (unsigned) chromatic border. Hence, a value of $100 \%$ indicates that motion was always perceived in the direction of displacement for the border undergoing chromatic contrast reversal. Conversely, a value of $0 \%$ indicates that motion was always perceived in the direction that preserved sign of chromatic contrast (and luminance contrast, for nonisoluminant conditions). When little or no luminance contrast is present, motion is perceived in the unsigned direction. However, when luminance contrast is added to the gratings or as phase displacement is increased, there is greater tendency to perceive motion in the signed direction (after Dobkins and Albright, 1993). These results nicely mirror those seen for MT neurons.

isoluminant stimuli under all conditions (Gegenfurtner et al., 1994). Specifically, for low temporal frequency stimuli, the chromatic contrast level required to elicit responses in MT was reported to be higher than the psychophysical threshold obtained from a monkey performing a direction identification task. Our stimuli possessed temporal frequencies $(7.5 \mathrm{~Hz}$ to approximately $14 \mathrm{~Hz}$ ) that apparently produce good correspondence between MT and psychophysical thresholds (Gegenfurtner et al., 1994), thereby increasing the likclihood that the activity we observed in MT contributes to our psychophysical results (Dobkins and Albright, 1993).

On the other hand, some aspects of our MT data clearly conflict with data obtained in human psychophysical experiments that have investigated the "equivalent luminance contrast" of moving heterochromatic gratings. Employing a motion nulling technique, Cavanagh and Anstis (1991) reported that a 0.5 cycle/degree red/green grating (r.m.s. cone contrast $=26 \%$ ) moving at $8 \mathrm{~Hz}$ was equivalent to an achromatic grating with $\sim 7 \%$ luminance modulation. Cavanagh and Anstis developed a model to explore the possibility that these results could be attributed to known scatter of isoluminant points across M-type retinal ganglion cells (Lee et al., 1988). Because their model grossly underestimated the perceptual equivalent luminance contrast of heterochromatic gratings, these authors concluded that the ability to perceive motion of isoluminant gratings could not be accounted for by such interunit variability. By contrast to these conclusions derived from psychophysical experiments, our results (Fig. 7), obtained using neuronal directional selectivity as a criterion, indicate that a 0.49 cycle/degree red/green (r.m.s. cone contrast $\sim 26 \%$ ) grating moving at $7.5 \mathrm{~Hz}$ is equivalent to a $2.5 \%$ achromatic grating. This equivalence value is fairly well predicted by models of magnocellular interunit variability (cf. Fig. 20, Cavanagh and Anstis, 1991), suggesting that activity within the magnocellular stream may be sufficient to account for the use of chromatic sign in MT. The apparent discrepancy between neuronal and psychophysical equivalence values suggests that MT may contribute only partially to chromatic motion correspondence revealed behaviorally.

\section{Other potential sites for color-facilitated motion correspondence}

In view of the aforementioned evidence for partial dissociations between neural activity in area MT and perception, it is worth exploring the possibility that other brain regions are involved. In order for a particular brain region to support the use of color for motion correspondence, it is prerequisite that the neurons in this area (1) are selective for direction of motion and (2) can use chromatic properties of an image to elicit directional selectivity. One possibility is that these two conditions are fulfilled within the various cortical components of the dorsal stream, other than MT. Of particular interest are the directionally selective neurons located in layer $4 \mathrm{~B}$ of striate cortex (V1), which provides direct input to MT. Some of these neurons reportedly respond to motion of isoluminant stimuli (Hubel and Livingstone, 1990). It remains to be determined, however, whether they exploit both signed and unsigned chromatic contrast cues. The presumed magnocellular divisions of area V2 ("thick" stripes), which receive direct input from layer $4 \mathrm{~B}$ and also project to MT, are another potential substrate for color-facilitated motion correspondence. Appropriate experiments addressing this possibility have yet to be performed.

Alternatively, the possibility exists that activity within the ventral cortical stream underlies chromatic motion correspondence. All lines of evidence suggest, however, that directional selectivity is not a salient property of the cells within this pathway (Van Essen and Zeki, 1978; Zeki, 1978a,b). While one might still argue that the few neurons in the ventral areas that do express strong directional selectivity are sufficient to account for motion perception at isoluminance, appropriate neurophysiological experiments have yet to be conducted.

\section{Building directionally selective units from "early" chromatic signals}

The ùse of chromatically unsigned cues for motion correspondence: magnocellular contribution?. When presented with a nonisoluminant stimulus cycling between red and green, the firing rates of "on-center" magnocellular neurons increase when the brighter of the two colors enters the receptive field (and vice versa for "off-center" cells). When the red and green are of equal luminance, however, many cells respond with equal magnitude to each chromatic change, regardless of the direction of change. 
Since chromatic changes occur twice within each red/green cycle, the response occurs at twice the temporal alternation frequency and the phenomenon has been dubbed "frequency doubling" (Schiller and Colby, 1983; Lee et al., 1988, 1989a-c; Logothetis et al., 1990).

Bearing this in mind, we propose a simple mechanism to explain the results of Experiment I in terms of activity among a population of contiguous on-center magnocellular neurons. The characteristics of this mechanism are illustrated in a highly schematic form in Figure 10. At isoluminance (Fig. 10, center panel) the spatiotemporal "flow" of neuronal activity is in the direction of the unsigned chromatically defined contour. When the heterochromatic grating is not isoluminant (Fig. 10, bottom panel), however, the flow of activity is in the direction in which sign of luminance and chromatic contrast are preserved. Motion is detected by spatiotemporal analysis of these activity patterns at a subsequent neuronal stage. This model thus readily accounts for both neurophysiological (reported herein) and psychophysical data (Dobkins and Albright, 1993) obtained using contrastreversing stimuli undergoing small spatial phase displacements. It does not, however, account for motion correspondence based upon chromatic sign, an important issuc that is addressed in the following section.

The use of chromatic sign for motion correspondence. Experiment II revealed the existence of a motion mechanism that relies upon chromatic sign. Might activity within the magnocellular pathway account for this phenomenon or must we propose a parvocellular contribution? A magnocellular subtype (Type IV) found in the retina and LGN may carry information aboul chromatic sign. Type IV cells possess red inhibitory surrounds and therefore appear to exhibit some chromatic opponency (De Valois et al., 1966; Wiesel and Hubel, 1966; Kruger, 1977; Schiller and Malpeli, 1978; Derrington et al., 1984). Since our heterochromatic stimuli were presented under conditions that are thought to activate Type IV neurons (Smith et al., 1991), we cannot rule out the possibility that these neurons contributed to the observed effects of chromatic sign on directional selectivity in MT.

A second potential magnocellular mechanism may be found in the fact that the red/green luminance "balance point" varies among the population of magnocellular LGN neurons (and M-retinal ganglion cells), assuring that, as a population, magnocellular neurons can never be truly silenced (Logothetis et al., 1990). The degree to which motion processing areas actually use this type of information, however, remains a matter of debate (see above).

Finally, there are several places in the primate visual system that allow at least some input from the parvocellular (coloropponent) to the magnocellular stream, which might also contribute to the observed influence of chromatic sign. In V1, for example, direct connections have been observed linking cortical laminae that contain color-selective neurons with laminae that contain directionally selective neurons (Yoshioka and Lund, 1990). In extrastriate visual cortex, direct connections have been found between areas V4 and MT (Maunsell and Van Essen, 1983b; Desimone and Ungerleider, 1986; Ungerleider and Desimone, 1986). Furthermore, neurophysiological studies have shown that signals from both parvocellular and magnocellular layers of the LGN converge onto superficial layers of VI (Malpeli et al., 1981; Nealey and Maunsell, 1991). While similar experiments have demonstrated only a wcak parvocellular input to area MT (Nealey et al., 1989; Maunsell et al., 1990), our

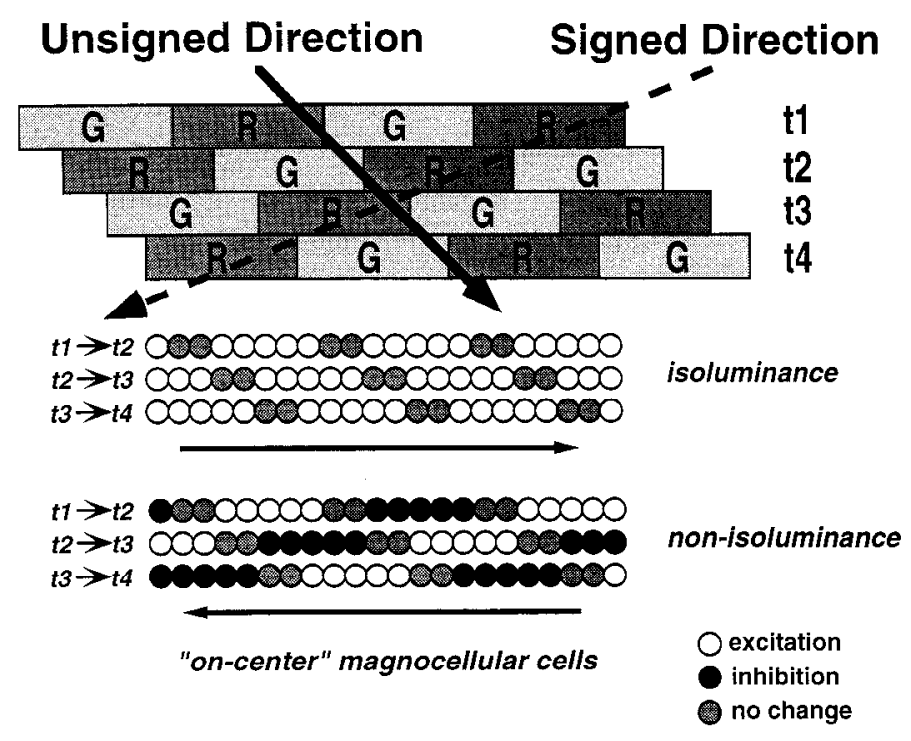

Figure 10. Activity among a population of "on-center" magnocellular neurons signal motion in the unsigned direction at isoluminance, and in the signed direction away from isoluminance. The upper panel depicts the spatial configuration of our red/green contrast-reversing grating (used in Experiment I) at four different moments in time. In this example, the proximal unsigned cue moves rightward (solid arrow), while the signed cue moves leftward, preserving color (and luminance) correspondence over time and space (dashed arrow). Below the grating we have shown presumed activation state within a population of contiguous "on-center" magnocellular neurons as a function of the visual stimulation sequence (e g., at the transition from $t l \rightarrow t$ ?). When the red/ green grating is isoluminant (center panel), each neuron fires at the instant a chromatic substitution occurs within its receptive field, regardless of the direction of the substitution (open circles). Under such conditions, the spatiotemporal "flow" of active neurons is in the direction of the unsigned chromatically defined contour which can explain motion correspondence in the unsigned border cue direction (e.g., Figs. 2,9 ). The bottom panel illustrates the effects that the addition of luminance contrast to our heterochromatic stimulus should have on the same population of cells. Under this condition, each "on-center" neuron will be excited whenever the brighter of the two chromatic phases (in this case, green) enters its receptive field (open circles) and inhibited when the dimmer phase enters (solid circles) (shaded circles depict no change in responsivity). In consequence, the spatiotemporal "flow" is now in the opposite direction, that is, the direction in which sign of luminance and chromatic correspondence are both conserved. Furthermore, in the case of an achromatic grating, the pattern of activity would be expected to be the same as that produced by heterochromatic gratings containing luminance modulation - that is, an excitatory response to the brighter of the two luminance phases. Under achromatic conditions, therefore, the spatiotemporal flow will also be in the signed direction. This model thus readily accounts for our neurophysiological data (Fig. 3) as well as our previous human psychophysical data obtained using contrast-reversing stimuli undergoing small spatial phase displacements (from Dobkins and Albright, 1993).

results imply that a greater parvocellular contribution may be revealed if appropriate heterochromatic stimuli are employed. In any event, it seems that there are numerous means by which parvocellular and magnocellular signals might mingle. Interactions of this sort might influence motion processing by creating motion detectors that are not themselves selective for color, yet access information about chromatic sign to detect direction of motion.

\section{References}

Agonie C, Gorea A (1993) Equivalent luminance contrast of red-green drifting stimuli: dependence on luminance-color interactions and on the psychophysical task. J Opt Soc Am 10:1341-1352. 
Aguilar M, Stiles WS (1954) Saturation of the rod mechanism of the retina at high levels of stimulation. Opt Acta 1:59-65.

Albright TD (1984) Direction and orientation selectivity of neurons in visual area MT of the macaque. J Neurophysiol 52:1106-1130.

Albright TD (1992) Form-cue invariant motion processing in primate visual cortex. Science 255:1141-1143.

Anstis SM (1970) Phi movement as a subtractive process. Vision Res 10:1411-1430.

Anstis S, Mather G (1985) Effects of luminance and contrast on direction of ambiguous apparent motion. Perception 14:167-179.

Baker JF, Petersen SE, Newsome WT, Allman JM (1981) Visual response properties of neurons in four extrastriate visual areas of the owl monkey (Aotus trivirgatus): a quantitative comparison of the mcdial (M), dorsomedial (DM), dorsolateral (DL), and middle temporal (MT) areas. J Neurophysiol 45:387-406.

Boynton RM (1986) A system of photometry and colorimetry based on cone excitations. Color Res Appl 11:244-252.

Bruce CJ, Goldberg ME (1985) Primate frontal eye fields. I. Single neurons discharging before saccades. $J$ Neurophysiol 53:603-635.

Cavanagh $P$ (1988) Interunit variability of equiluminance points does not mediate the contribution of color to motion. Invest Ophthalmol Vis Sci $29: 327$

Cavanagh P, Anstis SM (1988) Red/green opponent-color input to motion at low spatial frequencies. Soc Neurosci Abstr 14:456.

Cavanagh P, Anstis SM (1991) The contribution of color to motion in normal and color-deficient observers. Vision Res 31:2109-2148.

Cavanagh P, Favreau OE (1985) Color and luminance share a common motion pathway. Vision Res 25:1595-1601.

Cavanagh P, Tyler CW, Favreau OE (1984) Perceived velocity of moving chromatic gratings. J Opt Soc Am 1:893-899.

Cavanagh P, MacLeod DIA, Anstis SM (1987) Equiluminance: spatial and temporal factors and the contribution of blue-sensitive cones. $\mathbf{J}$ Opt Soc Am 4:1428-1438.

Charles ER, Logothetis NK (1989) The responses of middle temporal (MT) neurons to isoluminant stimuli. Invest Ophthalmol Vis Sci 30: 427.

Corbetta M, Miezen FM, Dobmeyer S, Shulman GL, Peterson SE (1990) Attentional modulation of neural processing of shape, color, and velocity in humans. Science 248:1556-1559.

Cushman WB, Levinson JZ (1983) Phase shift in red and green counterphase flicker at high frequencies. J Opt Soc Am 73:1557-1561.

De Monasterio FM (1978) Properties of concentrically organized X and $Y$ ganglion cells of macaque retina. J Physiol 41:1394-1417.

De Monasterio FM, Gouras P (1975) Functional properties of ganglion cells of the rhesus monkey retina. J Physiol (Lond) 251:167-195.

Derrington AM, Badcock DR (1985) The low level motion system has both chromatic and luminance inputs. Vision Res 25:1879-1884.

Derrington AM, Lennie P (1984) Spatial and temporal contrast sensitivities of neurons in the lateral geniculate nucleus of macaque. $\mathbf{J}$ Physiol (Lond) 357:219-240.

Derrington AM, Krauskopf J, Lennie P (1984) Chromatic mechanisms in lateral geniculate nucleus of macaque. J Physiol (Lond) 357:241265.

Desimone R, Ungerleider LG (1986) Multiple visual areas in the caudal superior temporal sulcus of the macaque. J Comp Neurol 248; 164-189.

De Valois RL, Abramov I, Jacobs GH (1966) Analysis of response patterns of LGN cells. J Opt Soc Am 56:966-977.

DeYoe EA, Van Essen DC (1985) Segregation of efferent connections and receptive field properties in visual area V2 of the macaque. Nature 317:58-61.

Dobkins KR, Albright TD (1990) Color facilitates motion correspondence in visual area MT. Soc Neurosci Abstr 16:1220.

Dobkins KR, Albright TD (1991a) What happens if it changes color when it moves? Invest Ophthalmol Vis Sci 32:823.

Dobkins KR, Albright TD (1991b) The use of color- and luminancedefined edges for motion correspondence. Soc Neurosci Abstr 17:524.

Dobkins KR, Albright TD (1993) What happens if it changes color when it movcs?: psychophysical experiments on the nature of chromatic input to motion detectors. Vision Res 33:1019-1036.

Flitcroft DI (1989) The interactions between chromatic aberration, defocus and stimulus chromaticity: implications for visual physiology and colorimetry. Vision Res 29:349-360.

Gegenfurtner KR, Kiper DC, Beusmans JMH, Carandini M, Zaidi Q, Movshon JA (1994) Chromatic properties of neurons in macaque MT. Vis Neurosci in press.
Gorea A, Papathomas TV (1989) Motion processing by chromatic and achromatic visual pathways. J Opt Soc Am [A] 6:590-602.

Gorea A, Lorenceau J, Bagot J, Papathomas TV (1990) Color-based motion perception may be stronger under equiluminant than nonequiluminant conditions. Invest Ophthalmol Vis Sci 31:518.

Gouras P (1968) Identification of cone mechanisms in monkey ganglion cells. J Physiol (Lond) 199:533-547.

Gouras P (1969) Antidromic responses of orthodromically identified ganglion cells in the monkey retina. J Physiol (Lond) 204:407-419.

Gouras P, Fggers HM (1982) Retinal responses to color contrast. Invest Ophthalmol Vis Sci $22: 176$

Gouras P, Zrenner E (1979) Enhancement of luminance flicker by color-opponent mechanisms. Science 205:587-589.

Gouras P, Zrenner E (1981) Color coding in primate retina. Vision Res 21:1591-1598.

Graham N (1989) Visual pattern analyzers. New York: Oxford UP.

Green M (1989) Color correspondence in apparent motion. Percept Psychophys 45:15-20.

Hering E (1893) Ueber den Einfluss der Macula Lutea auf spectrale Farbengleichungen. Pfluegers Arch 54:277-312.

Howarth PA, Bradley A (1986) The longitudinal chromatic aberration of the human eye and its correction. Vision Res 26:361-366.

Hubel DH, Livingstone MS (1990) Color and contrast sensitivity in the lateral geniculate body and primary visual cortex of the macaque monkey. J Neurosci 10:2223-2237.

Hubel DH, Wiesel TN (1972) Laminar and columnar distribution of geniculo-cortical fibers in the macaque monkey. J Comp Ncurol 146: $421-450$

Hurlbert AC, Logothetis NK, Charles ER, Schiller PH (1987) The processing of color and luminance in monkeys. 2. Physiology. Soc Neurosci Abstr 13:204.

Judge SJ, Richmond BJ, Chu FC (1980) Implantation of magnetic search coils for measurement of eye position: an improved method. Vision Res 20:535-538.

Kaiser PK, Lee BB, Martin PR, Valberg A (1990) The physiological basis of the minimally distinct border demonstrated in the ganglion cells of the macaque retina. J Physiol (Lond) 422:153-183.

Kelly DH (1983) Spatiotemporal variation of chromatic and achromatic contrast thresholds. J Opt Soc Am 73:742-750.

Kolers PA (1972) Aspects of motion perception. Oxford: Pergamon.

Kruger J (1977) Stimulus dependent colour specificity of monkcy lateral geniculate neurones. Exp Brain Res 30:297-311.

Kruger J (1979) Responses to wavelength contrast in the afferent visual systems of the cat and rhesus monkey. Vision Res 19:1351-1358.

Lee BB, Martin PR, Valberg A (1988) The physiological basis of heterochromatic flicker photometry demonstrated in the ganglion cells of the macaque retina. J Physiol (Lond) 404:323-347.

Lee BB, Martin PR, Valberg A (1989a) Sensitivity of macaque retinal ganglion cells to chromatic and luminance flicker. J Physiol (Lond) 414:223-243.

Lee BB, Martin PR, Valberg A (1989b) Amplitude and phase of response of macaque retinal ganglion cells to flickering stimuli. J Physiol (Lond) 414:245-263.

Lee BB, Martin PR, Valberg A (1989c) Nonlinear summation of Mand $\mathrm{L}$-cone inputs to phasic retinal ganglion cells of the macaquc. $J$ Neurosci 9:1433-1442.

Lee BB, Pokorny J, Smith VC, Martin PR, Valberg A (1990) Luminance and chromatic modulation sensitivity of macaque ganglion cells and human observers. J Opt Soc Am [A] 7:2223-2236.

Lindsey DT, Teller DY (1990) Motion at isoluminance: Discrimination/detection ratios for moving isoluminant gratings. Vision Res 30:1751-1761

Livingstone MS, Hubel DH (1984) Anatomy and physiology of a color system in the primate visual cortex. J Neurosci 4:309-356.

Livingstone MS, Hubel DH (1987a) Connections between layer 4B of area 17 and the thick cytochrome oxidase stripes of area 18 in the squirrel monkey. J Neurosci 7:3371-3377.

Livingstone MS, Hubel DH (1987b) Psychophysical evidence for separate channels for the perception of form, color, movement, and depth. J Neurosci 7:3416-3468.

Logothetis NK, Charles ER (1990) The minimum motion technique applied to determine isoluminance in psychophysical experiments with monkeys. Vision Res 30:829-838.

Logothetis NK, Schiller PH, Charles ER, Hurlbert AC (1990) Perceptual deficits and the activity of the color-opponent and broadband pathways at isoluminance. Science 247:214-217. 
Lund JS, Boothe RG (1975) Interlaminar connections and pyramidal neuron organization in the visual cortex, area 17 , of the macaque monkey. J Comp Neurol 159:305-334.

Lund JS, Lund RD, Hendrickson AE, Bunt AH, Fuchs AF (1975) The origin of efferent pathways from the primary visual cortex, area 17, of the macaque monkey as shown by retrograde transport of horseradish peroxidase. J Comp Neurol 164:287-304.

Malpeli JG, Schiller PH, Colby CL (1991) Response properties of single cells in the monkey striate cortex during reversible inactivation of individual lateral geniculate nuclei. J Neurophysiol 46:1102-11 19.

Marc RE, Sperling HG (1977) Chromatic organization of primate cones. Science 196:454-456.

Maunsell JHR, Van Essen DC (1983a) Functional properties of neurons in middle temporal visual area of the macaque monkey. I. Selectivity for stimulus direction, speed and orientation. J Neurophysiol 49:1127-1147.

Maunsell JHR, Van Essen DC (1983b) The connections of the middle temporal visual area (MT) and their relationship to a cortical hierarchy in the macaque monkey. $\mathrm{J}$ Neurosci 3:2563-2586.

Maunsell JHR, Nealey TA, DePriest DD (1990) Magnocellular and parvocellular contributions to responses in the middle temporal visual area (MT) of the macaque monkey. J Neurosci 10:3323-3334.

Merigan HM, Maunsell JHR (1990) Macaque vision after magnocellular lateral geniculate lesions. Vis Neurosci 5:347-352.

Merigan WH, Byrne CE Maunsell JHR (1991a) Does primate motion perception depend on the magnocellular pathway? J Neurosci 11: 3422-3429.

Merigan WH, Pasternak T, Ferrera V, Maunsell JHR (1991b) Permanent deficits in speed discrimination after MT/MST lesions in macaque monkeys. Soc Neurosci Abstr 17:8.

Mikami A, Newsome WT, Wurtz RH (1986) Motion selectivity in macaque visual cortex. II. Spatiotemporal range of directional interactions in MT and V1. J Neurophysiol 55:1328-1339.

Movshon JA, Kiper D, Beusmans J, Gegenfurtner K, Zaidi Q, Carandini M (1991) Chromatic properties of neurons in macaque MT. Soc Neurosci Abstr 17:524.

Mullen KT (1985) The contrast sensitivity of human colour vision to red-green and blue-yellow chromatic gratings. J Physiol (Lond) 359. $381-409$.

Mullen KT (1991) Colour vision as a post-receptoral specialization of the central visual field. Vision Res 31:119-130.

Mullen KT, Baker CL Jr (1985) A motion aftereffect from an isoluminant stimulus. Vision Res 25:685-688.

Mullen KT, Boulton JC (1989) Evidence for parallel processing of colour and motion. Invest Ophthalmol Vis Sci 30:324.

Nealey TA, Maunsell JHR (1991) Magnocellular and parvocellular contributions to the superficial layers of macaque striate cortex. Invest Ophthalmol Vis Sci 32:1117.

Nealey TA, DePriest DD, Maunsell JHR (1989) Magnocellular and parvocellular contributions to area MT in macaque extrastriate cortex. Soc Neurosci Abstr 15:161.

Nerger JL, Cicerone CM (1992) The ratio of $L$ cones to $M$ cones in the human parafoveal retina. Vision Res 32:879-888.

Newsome WT, Paré EB (1988) A selective impairment of motion perception following lesions of the middle temporal visual area (MT). J Neurosci 8:2201-2211.

Newsome WT, Gizzi MS, Movshon JA (1983) Spatial and temporal properties of neurons in macaque MT. Invest Ophthalmol Vis Sci 24:106.

Newsome WT, Wurtz RH, Dursteler MR, Mikami A (1985) Deficits in visual motion processing following ibotenic acid lesions of the middle temporal visual area of the macaque monkey. J Neurosci $5: 825-840$

Newsome WT, Mikami A, Wurtz RH (1986) Motion selectivity in macaque visual cortex. III. Psychophysics and physiology of apparent motion. J Neurophysiol 55:1340-1351.

Noorlander C, Koenderink JJ, den Ouden RJ, Wigbold Edens B (1983) Sensitivity to spatiotemporal colour contrast in the peripheral visual field. Vision Res 23:1-11.

Papathomas TV, Gorea A, Julesz B (1989) The strength of color and luminance in eliciting motion perception. Invest Ophthalmol Vis Sci 30:388.

Papathomas TV, Gorea A, Jules7. B (1991) Two carriers for motion correspondence: color and luminance. Vision Res 31:1883-1891.

Pasternak T, Maunsell JHR, Ferrera V, Merigan WH (1991b) Global motion perception after MT/MST lesions in a macaque. Soc Neurosci Abstr 17:8.

Pokorny J, Smith VC, Lutze M (1989) Heterochromatic modulation photometry. J Opt Soc Am 6:1618-1623.

Ramachandran VS, Gregory RL (1978) Does color provide an input to human motion detection? Nature 275:55-56.

Robinson DA (1963) A method of measuring eye movement using a scleral search coil in a magnetic field. IEEE Trans Biomed Eng 10: $137-145$

Robson JG (1966) Spatial and temporal contrast sensitivity functions of the visual system. J Opt Soc Am 56:1141-1142.

Rodman HR, Albright TD (1987) Coding of visual stimulus velocity in area MT of the Macaque. Vision Res 27:2035-2048.

Saito H, Tanaka K, Isono H, Yasuda M, Mikami A (1989) Directionally selective response of cells in the middle temporal area (MT) of the macaque monkey to the movement of equiluminous opponent color stimuli. Exp Brain Res 75:1-14.

Sato T (1988) Direction discrimination and pattern segregation with isoluminant chromatic random-dot cinematograms (RDC). Invest Ophthalmol Vis Sci 29:449.

Schiller PH, Colby CL (1983) The responses of single cells in the lateral geniculate nucleus of the rhesus monkey to color and luminance contrast. Vision Res 23:1631-1641.

Schiller PH, Malpeli JG (1978) Functional specificity of lateral geniculate nucleus laminae of the rhesus monkey. J Neurophysiol 41:788797.

Schiller PH, Logothetis NK, Charles ER (1990) Functions of the colour-opponent and broad-band channels of the visual system. Nature 343:68.

Sclar G, Maunsell JHR, Lennie P (1990) Coding of image contrast in the central visual pathway of the macaque monkey. Vision Res 30: $1-10$.

Shapley R, Kaplan E (1989) Responses of magnocellular LGN neurons and $M$ retinal ganglion cells to drifting heterochromatic gratings. Invest Ophthalmol Vis Sci 30:323.

Shipp S, Zeki S (1985) Segregation of pathways leading from area V2 to areas V4 and V5 of macaque monkey visual cortex. Nature 315: 322-325.

Simpson WA (1990) The use of different features by the matching process in short-range motion. Vision Res 30:1421-1428.

Smith VC (1991) Origin of perceptually measured phase shifts in the visual system. In: From pigments to perception (Valberg A, Lee BB, eds), pp 401-412. New York: Plenum.

Smith VC, Pokorny J (1972) Spectral sensitivity of color-blind observers and the cone photopigments. Vision Res 12:2059-2071.

Smith VC, Pokorny J (1975) Spectral sensitivity of the foveal cone photopigments between 400 and $500 \mathrm{~nm}$. Vision Res 15:161-171.

Snowden RJ, Treue S, Erickson RG, Andersen RA (1991) The response of area MT and V1 ncurons to transparent motion. J Ncurosci $11: 2768-2785$.

Stabell B, Stabell U (1981) Absolute spectral sensitivity at different retinal eccentricities. J Opt Soc Am 71:836-840.

Stabell U, Stabell B (1980) Variation in density of macular pigmentation and in short-wave cone sensitivity with eccentricity. J Opt Soc Am 70:706-711.

Stromeyer CF, Eskew RT, Kronauer RE (1990) The most sensitive motion detectors in humans are spectrally-opponent. Invest Ophthalmol Vis Sci [Suppl] 31:240.

Swanson WH, Pokorny J, Smith VC (1988) Effects of chromatic adaptation on phase-dependent sensitivity to heterochromatic flicker. $J$ Opt Soc Am [A] 5:1976-1982.

Teller DY, Lindsey DT (1993) Motion at isoluminance: motion dead zones in three-dimensional color space. J Opt Soc Am 10:1324-1331.

Thompson $P$ (1982) Perceived rate of movement depends on contrast. Vision Res 22:377-380.

Tootell RBH, Hamilton SL (1989) Functional anatomy of the second visual area (V2) in the macaque. J Neurosci 9:2620-2644.

Tootell RBH, Silverman MS, Hamilton SL, De Valois RL, Switkes E (1988) Functional anatomy of macaque striate cortex. III. Color. J Neurosci 8:1569-1593.

Ullman S (1980) The effect of similarity between line segments on the correspondence strength in apparent motion. Perception 9:617-626.

Ingerleider LG, Desimone R (1986) Cortical connections of visual area MT in the macaque. J Comp Neurol 248:190-222.

Valberg A, Lee BB, Kaiser PK, Kremers J (1992) Responses of ma- 
caque ganglion cells to movement of chromatic borders. J Physiol (Lond) 458:579-602.

van Esch JA, Koldenhof EE, van Doorn AJ, Koenderink JJ (1984) Spectral sensitivity and wavelength discrimination of the human peripheral visual field. J Opt Soc Am 1:443-450.

Van Essen DC, ZekiSM (1978) The topographic organization of rhesus monkey prestriate cortex. J Physiol (Lond) 277:193-266.

Van Essen DC, Maunsell JHR, Bixby JL (1981) The middle temporal area in the macaque: myeloarchitecture, connections, functional properties and topographic organization. J Comp Neurol 199:293-326.

Viénot $F$ (1980) Relations between inter- and intra-individual variability of color-matching functions. Experimental results. J Opt Soc Am 70:1476-1483.

Watson AB, Thompson PG, Murphy BJ, Nachmias J (1980) Summation and discrimination of gratings moving in opposite directions. Vision Res 20:341-347.

Watson AB, Nielson KRK, Poirson A, Fitzhugh A, Bilson A, Nguyen $\mathrm{K}$, Ahumada AJ (1986) Use of a raster framebuffer in vision research. Behav Res Methods Instr Comput 18:587-594.

Wiesel TN, Hubel DH (1966) Spatial and chromatic interactions in the lateral geniculate body of the rhesus monkey. J Neurophysiol 29: $1115-1156$

Wooten BR, Wald G (1973) Color vision mechanisms in the peripheral retinas of normal and dichromatic observers. J Gen Physiol 61:125145.

Wooten BR, Fuld K, Spillman L (1975) Photopic spectral sensitivity of the peripheral retina. J Opt Soc Am 65:334-342.

Yoshioka T, Lund JS (1990) Substrates for interaction of visual channels within area V1 of monkey visual cortex. Soc Neurosci Abstr 16: 707.

Zeki SM (1974) Functional organization of a visual area in the posterior bank of the superior temporal sulcus of the rhesus monkey. $J$ Physiol (Lond) 236:549-573.

Zeki SM (1978a) Uniformity and diversity of structure and function in rhesus monkey prestriate cortex. J Physiol (Lond) 277:273-290.

Zeki SM (1978b) Functional specialization in the visual cortex of the rhesus monkey. Nature 274:423-428.

Zeki SM, Watson JDG, Lueck CJ, Friston KJ, Kennard C, Frackowiak RSJ (1991) A direct demonstration of functional specialization in human visual cortex. J Neurosci 11:641-649. 